\title{
Mononuclear Copper Complexes with Tridentate Tris(N-Heterocyclic Carbene): Synthesis and Catalysis of Alkyne-Azide Cycloaddition
}

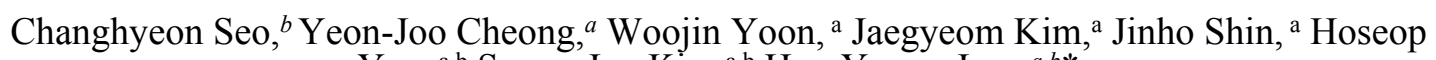
Yun, a,b Seung-Joo Kim, ${ }^{\text {a,b }}$ Hye-Young Jang ${ }^{a, b *}$

aDepartment of Energy Systems Research, Ajou University, Suwon 16499, Korea

${ }^{b}$ Department of chemistry, Ajou University, Suwon 16499, Korea

E-mail address of corresponding authors: hyjang2@ajou.ac.kr

I. NMR spectra of $\mathrm{Cu}$ complexes.

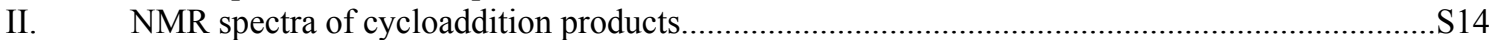

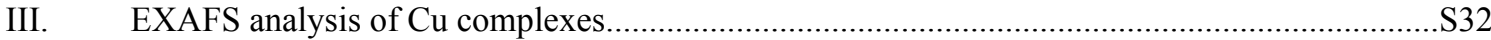

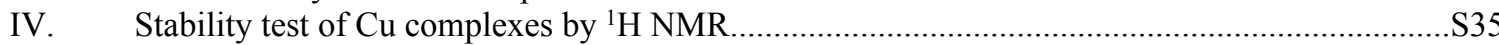




\section{NMR spectra of $\mathrm{Cu}$ complexes}

${ }^{1} \mathrm{H}$ NMR of 1,1'-((1H-Imidazole-3-ium-1,3-diyl)bis(propane-3,1-diyl))bis(3-methyl-1H-imidazol-3-ium) triiodide

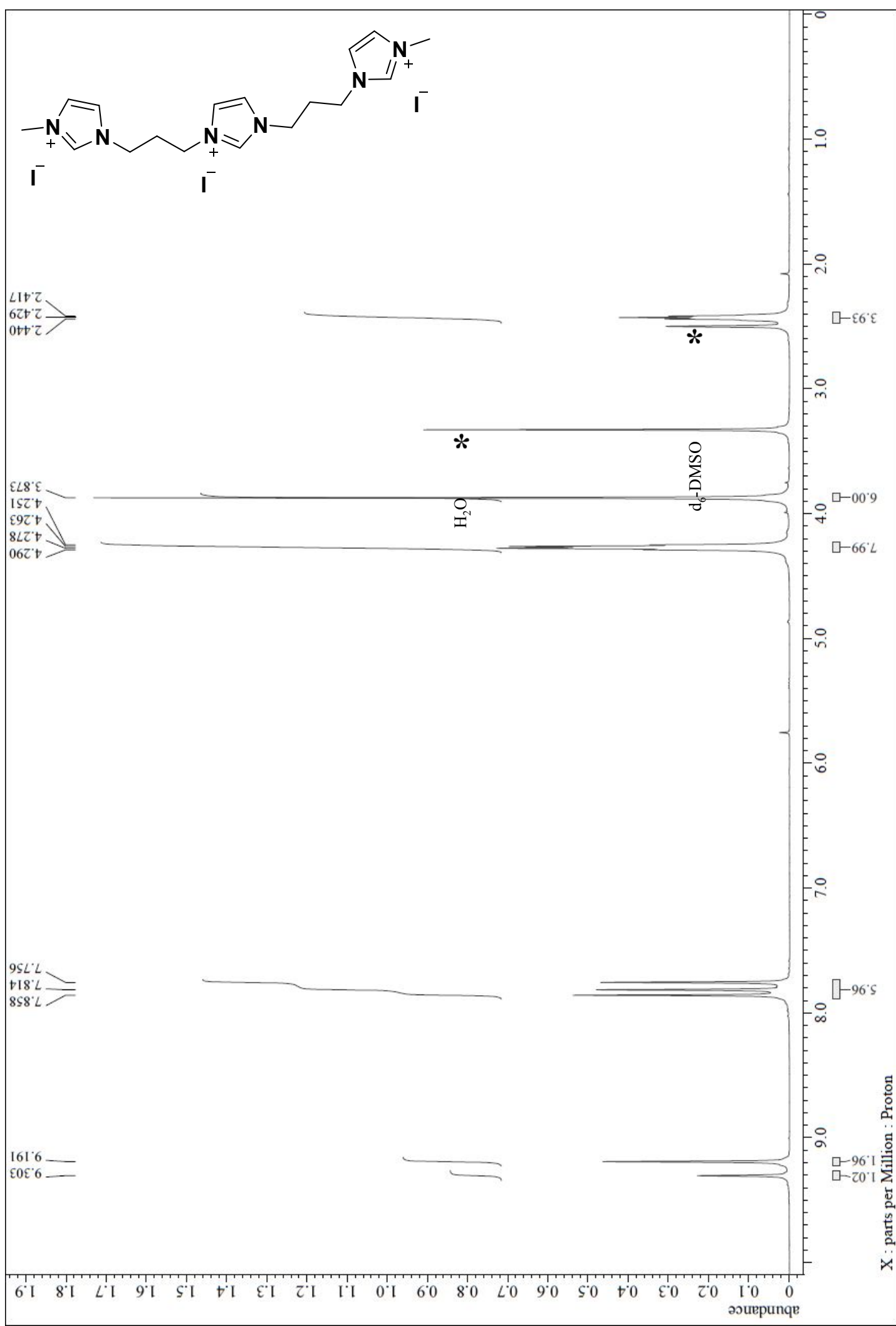


${ }^{13} \mathrm{C}$ NMR of 1,1'-((1H-Imidazole-3-ium-1,3-diyl)bis(propane-3,1-diyl))bis(3-methyl-1H-imidazol-3-ium) triiodide

7

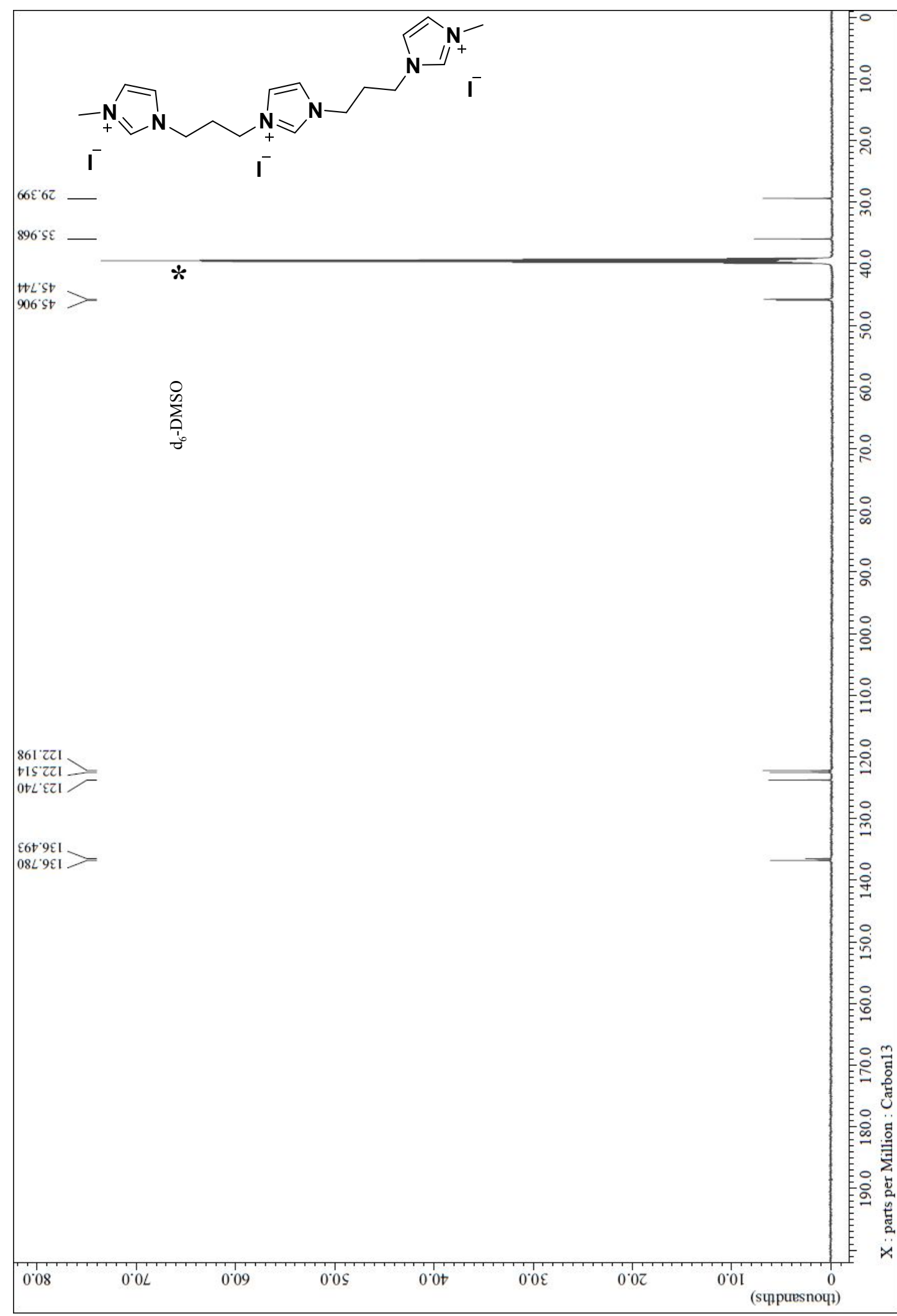


${ }^{1}$ H NMR of 1,1'-((1H-Imidazole-3-ium-1,3-diyl)bis(propane-3,1-diyl))bis(3-ethyl-1H-imidazol-3-ium) triiodide

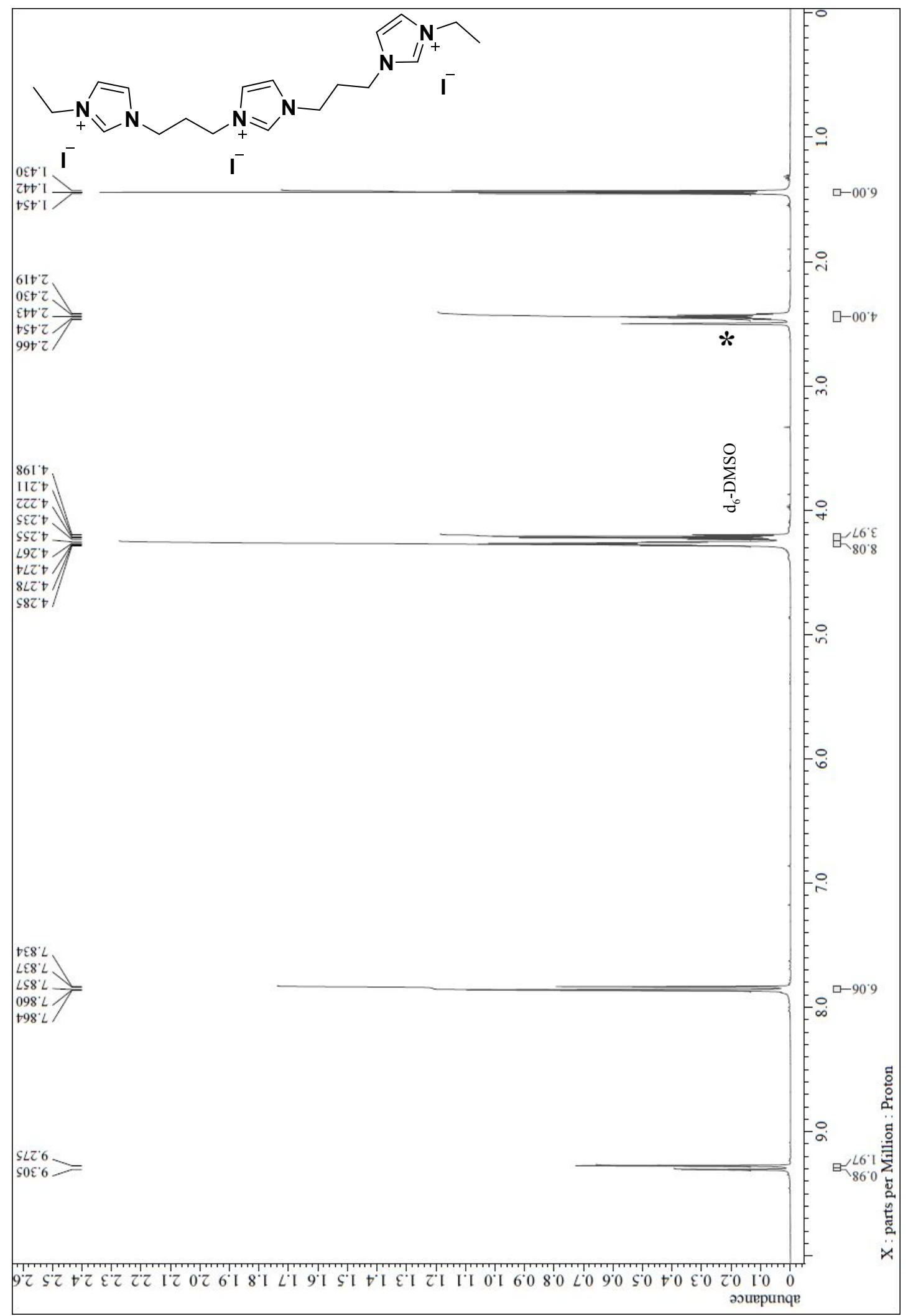


${ }^{13} \mathrm{C}$ NMR of 1,1'-((1H-Imidazole-3-ium-1,3-diyl)bis(propane-3,1-diyl))bis(3-ethyl-1H-imidazol-3-ium) triiodide

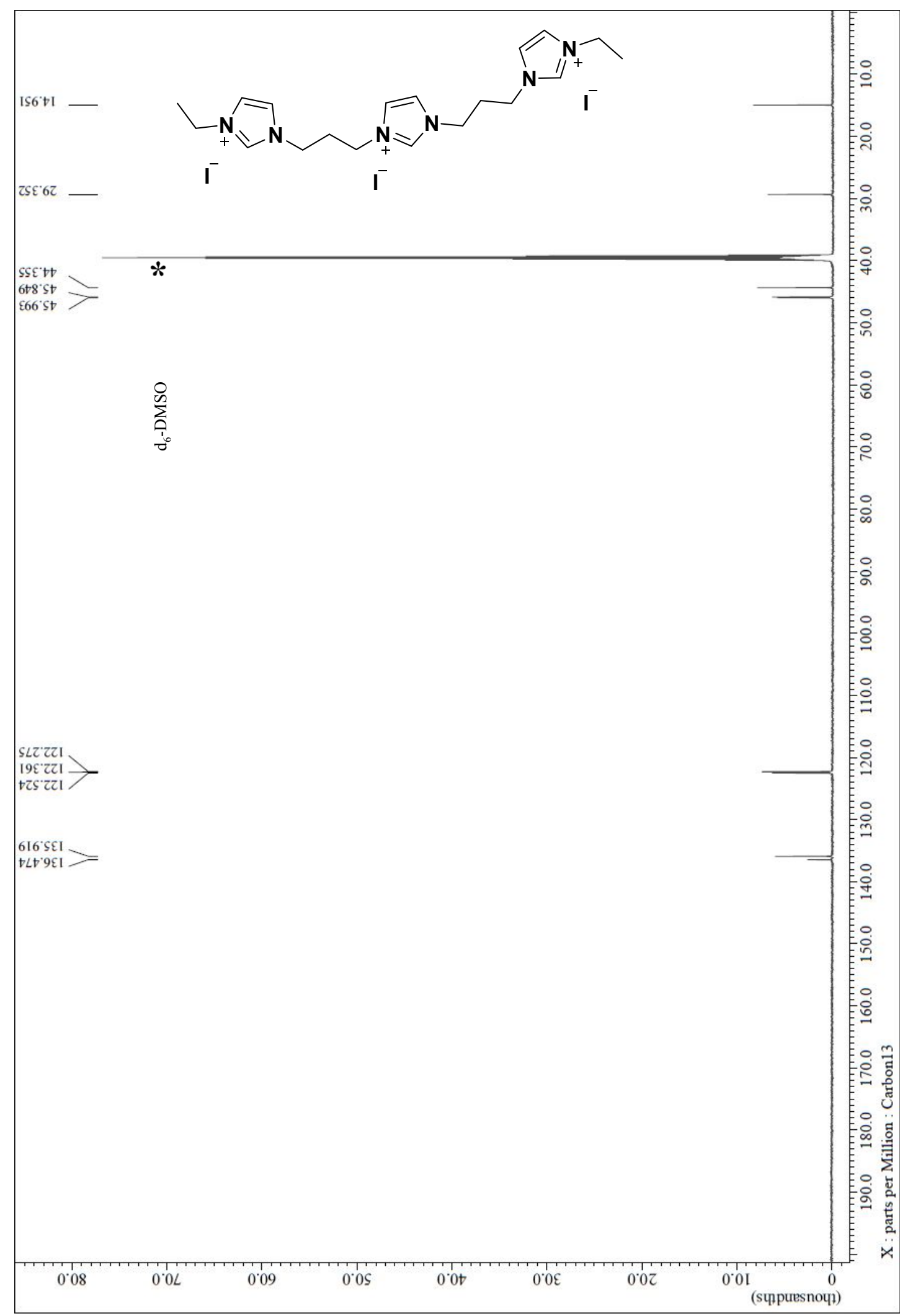


${ }^{1} \mathrm{H}$ NMR of 1,1'-((1H-Imidazole-3-ium-1,3-diyl)bis(propane-3,1-diyl))bis(3-methyl-1 $H$-benzo[d]imidazol-3ium) triiodide

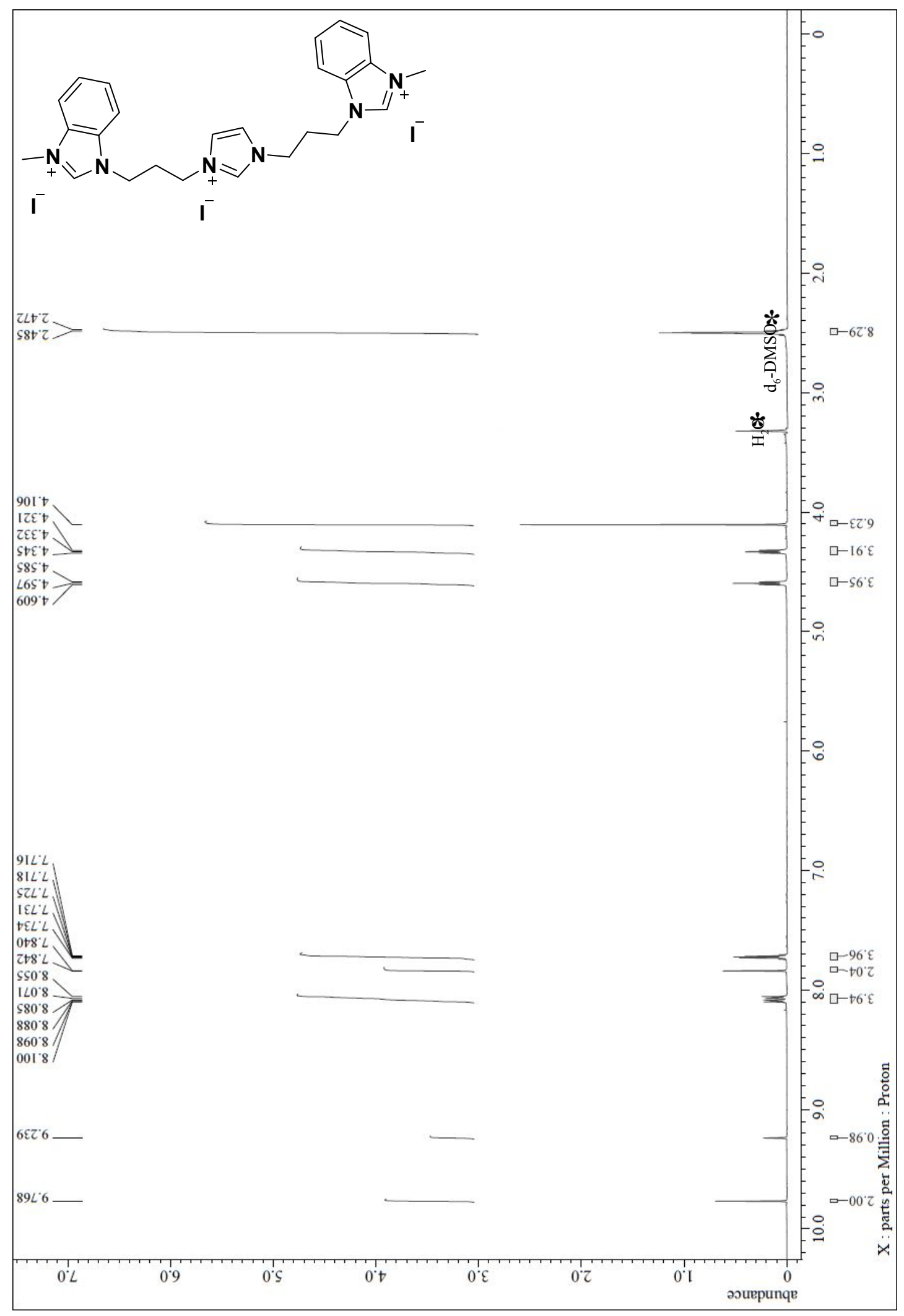


${ }^{13} \mathrm{C}$ NMR of 1,1'-((1H-Imidazole-3-ium-1,3-diyl)bis(propane-3,1-diyl))bis(3-methyl-1 $H$-benzo[d]imidazol3-ium) triiodide

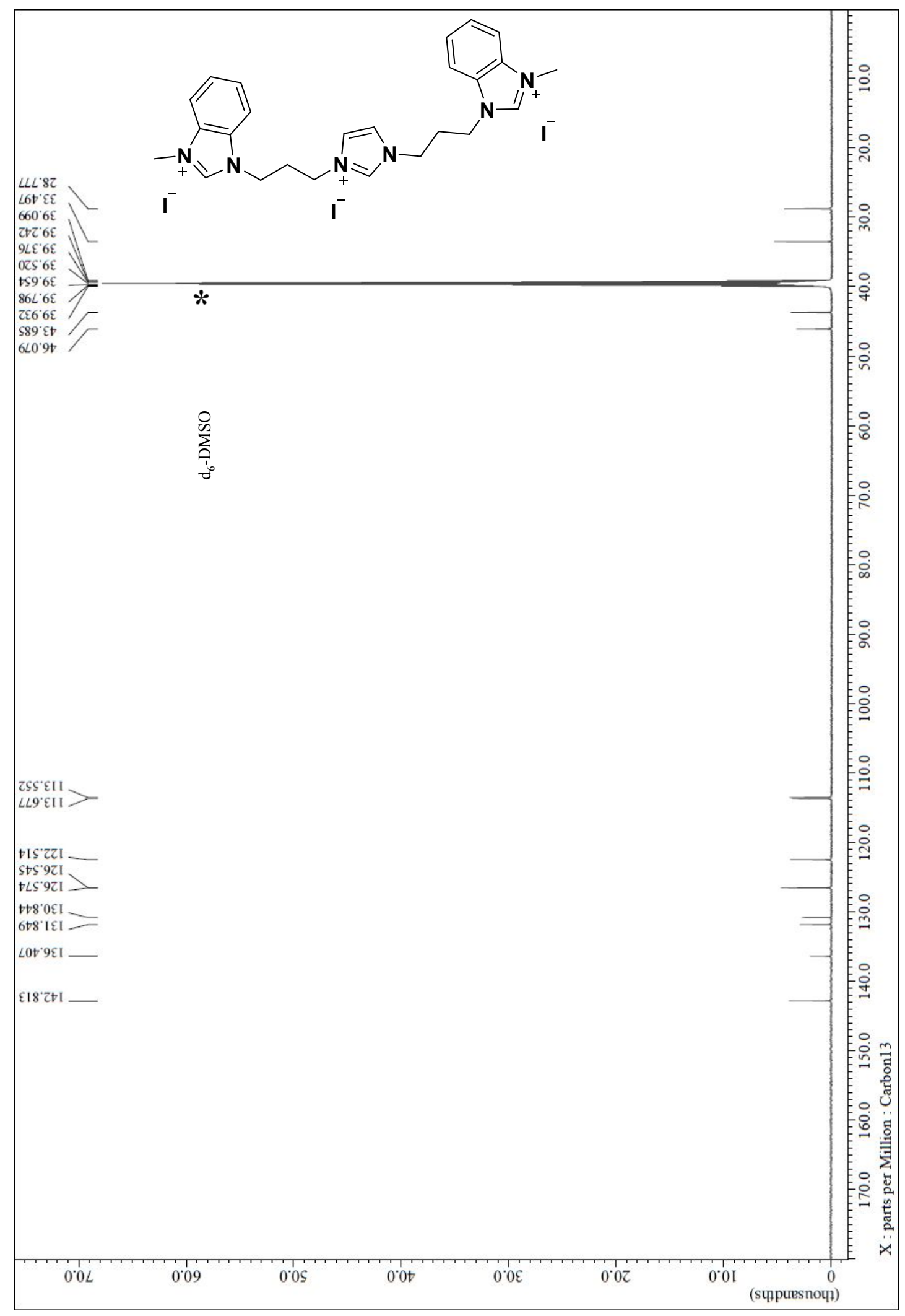


${ }^{1} \mathrm{H}$ NMR of Complex A

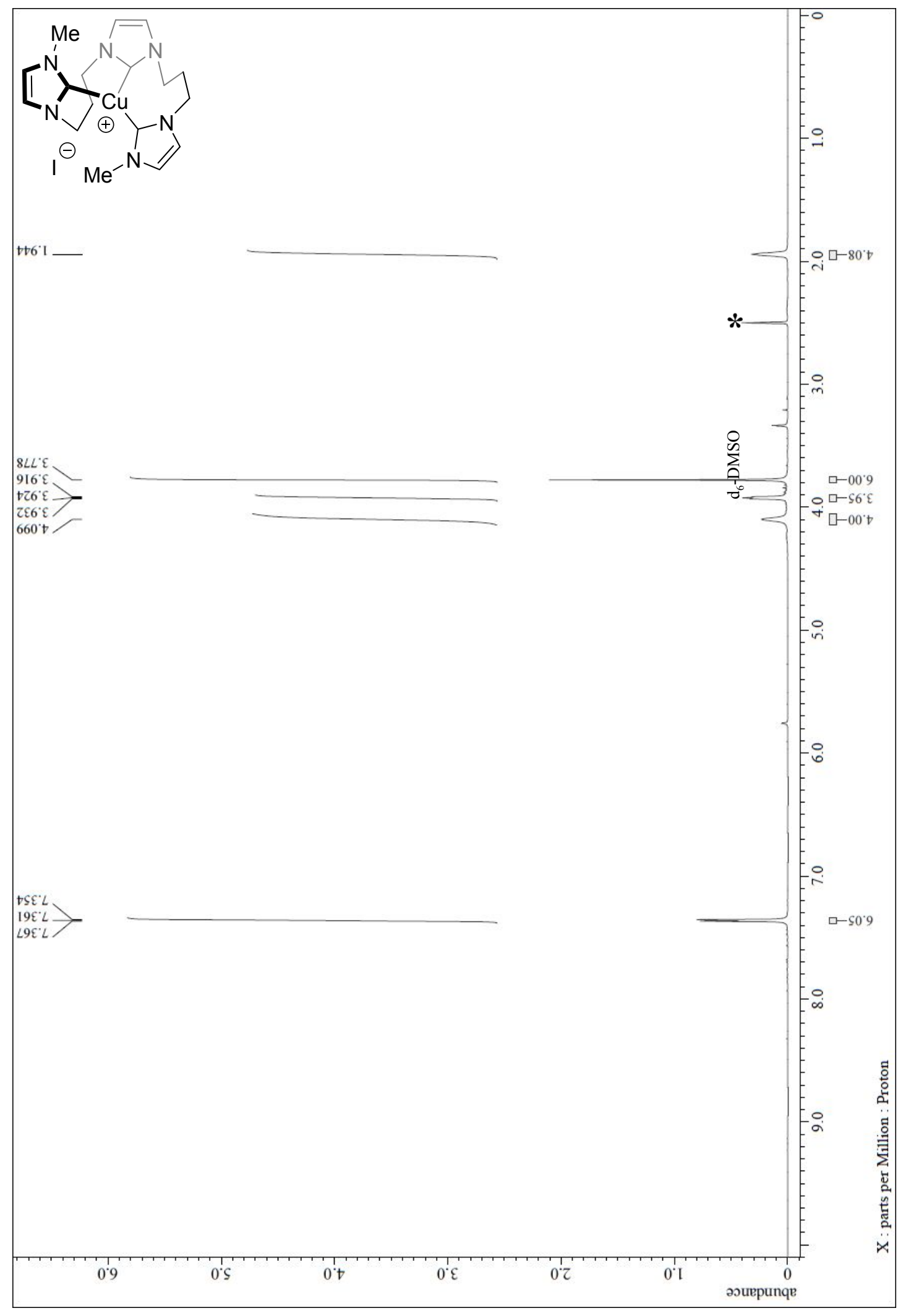


${ }^{13} \mathrm{C}$ NMR of Complex $\mathbf{A}$

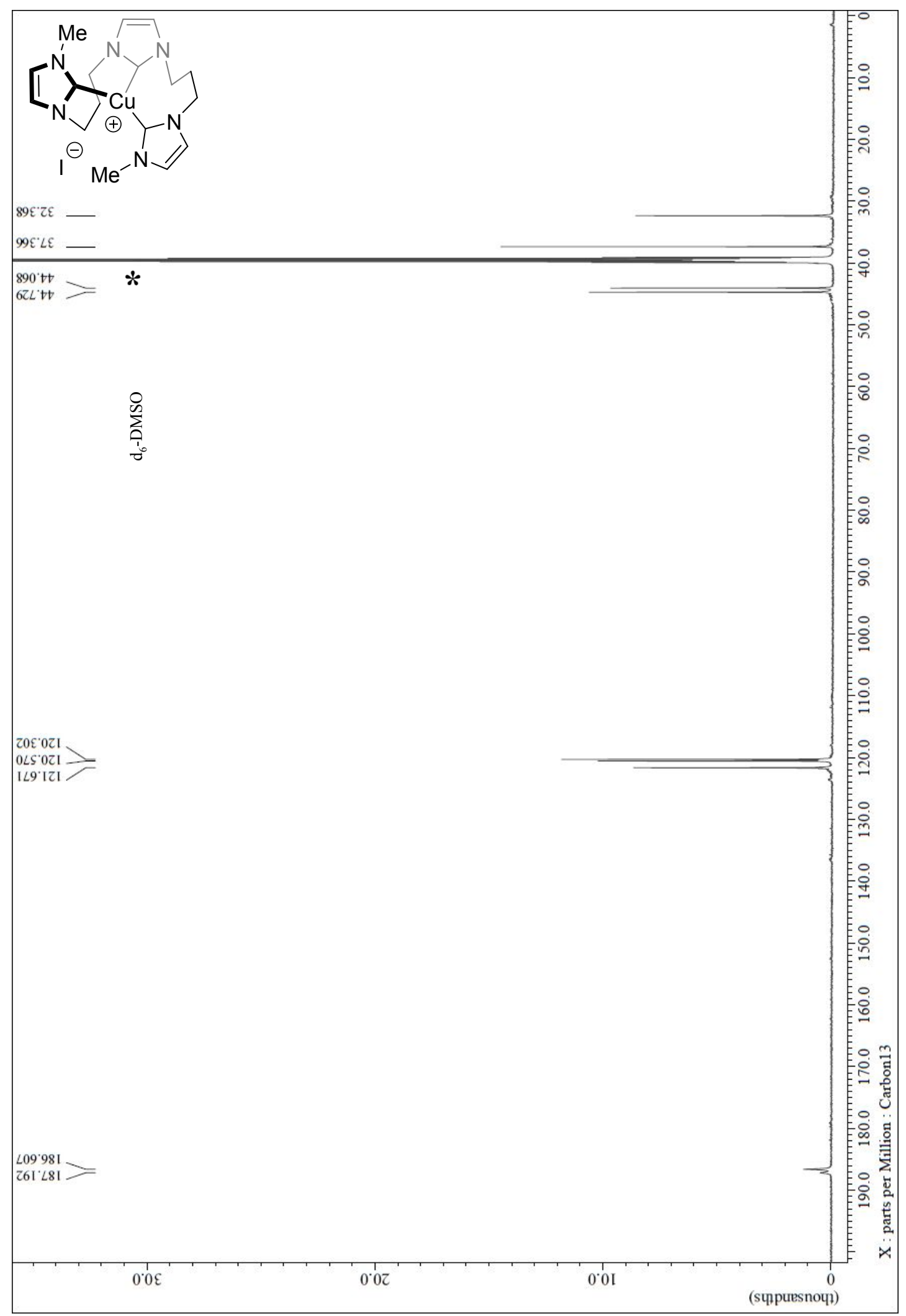


${ }^{1} \mathrm{H}$ NMR of Complex B

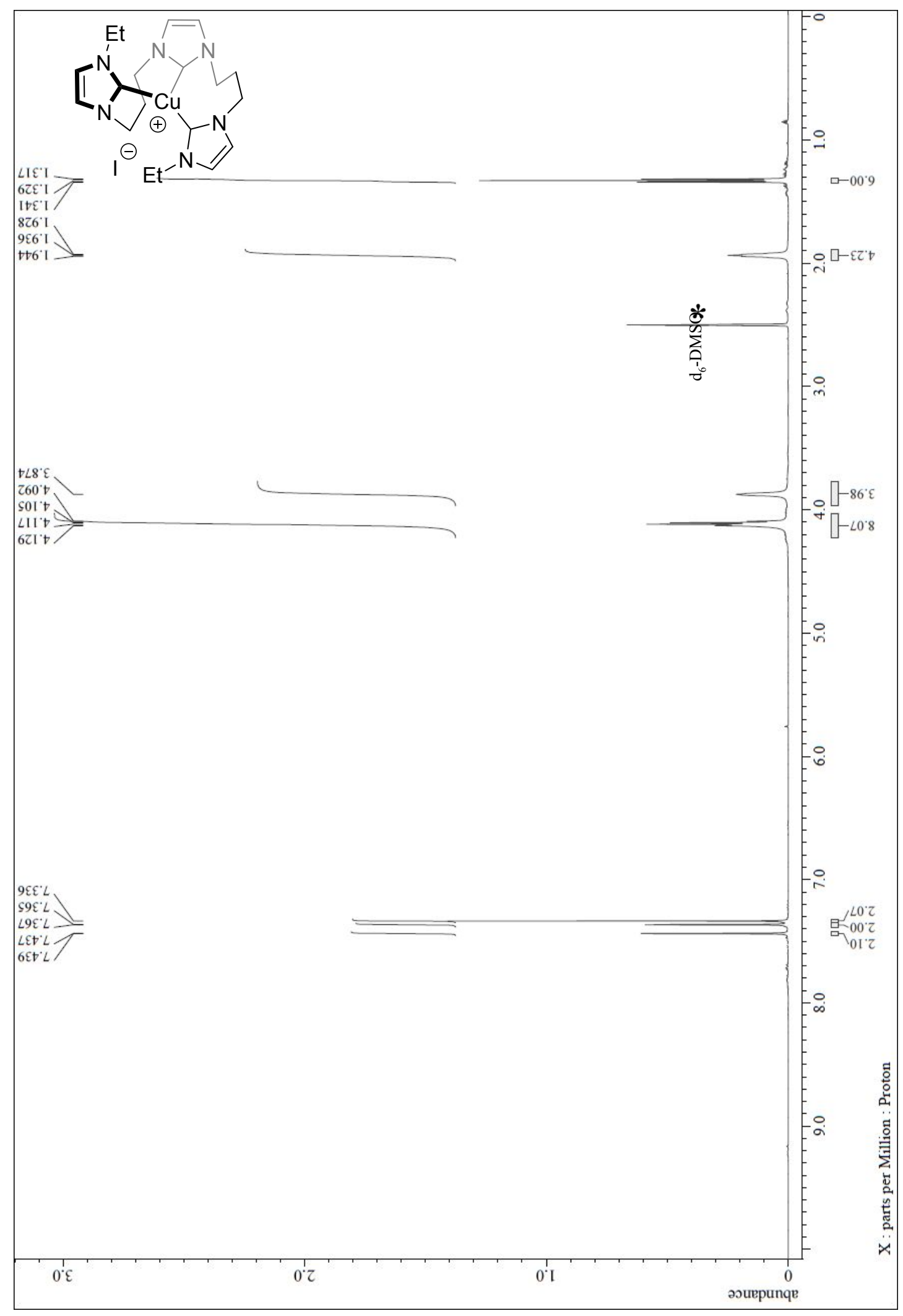


${ }^{13} \mathrm{C}$ NMR of Complex B

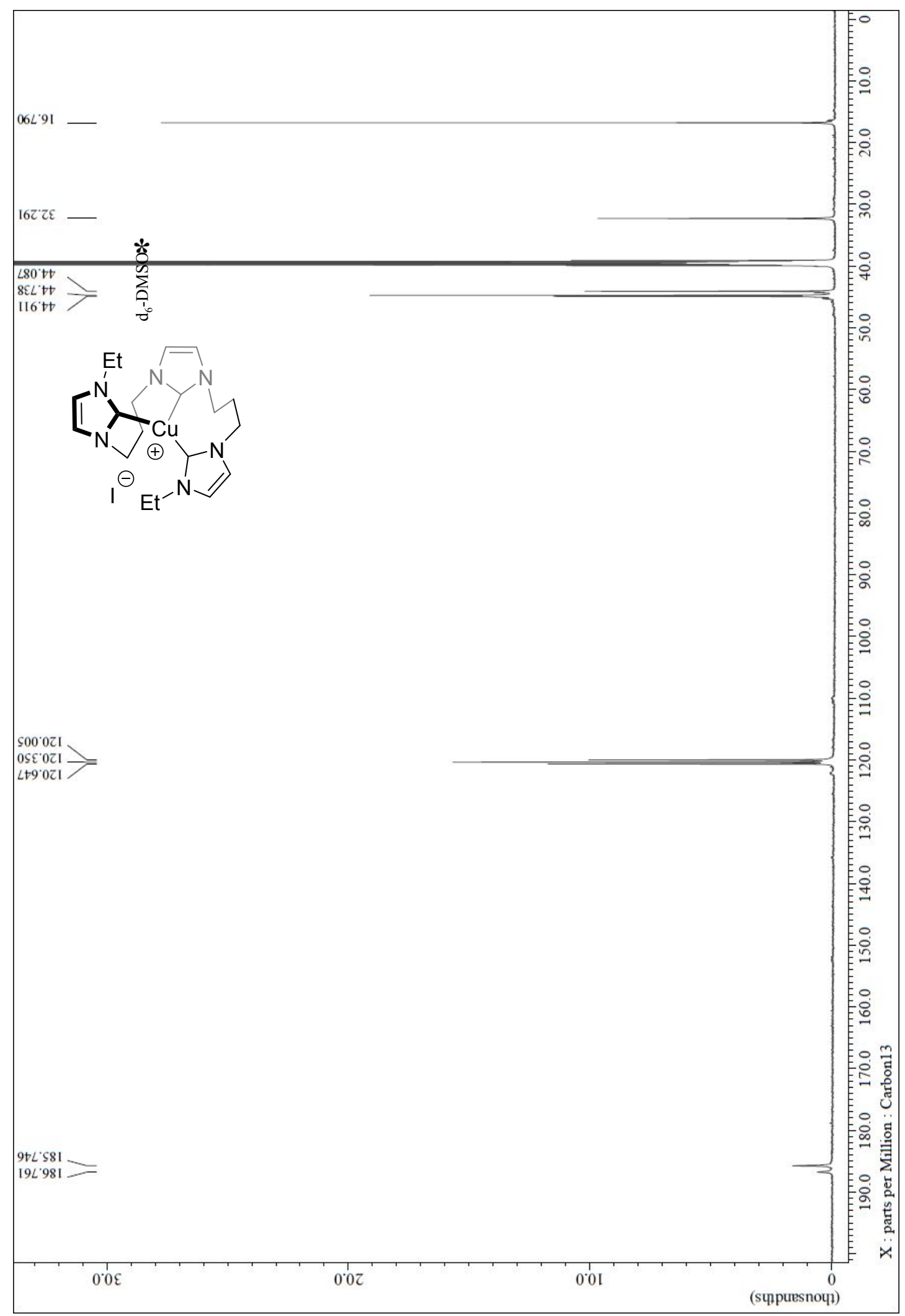


${ }^{1} \mathrm{H}$ NMR of Complex $\mathbf{C}$

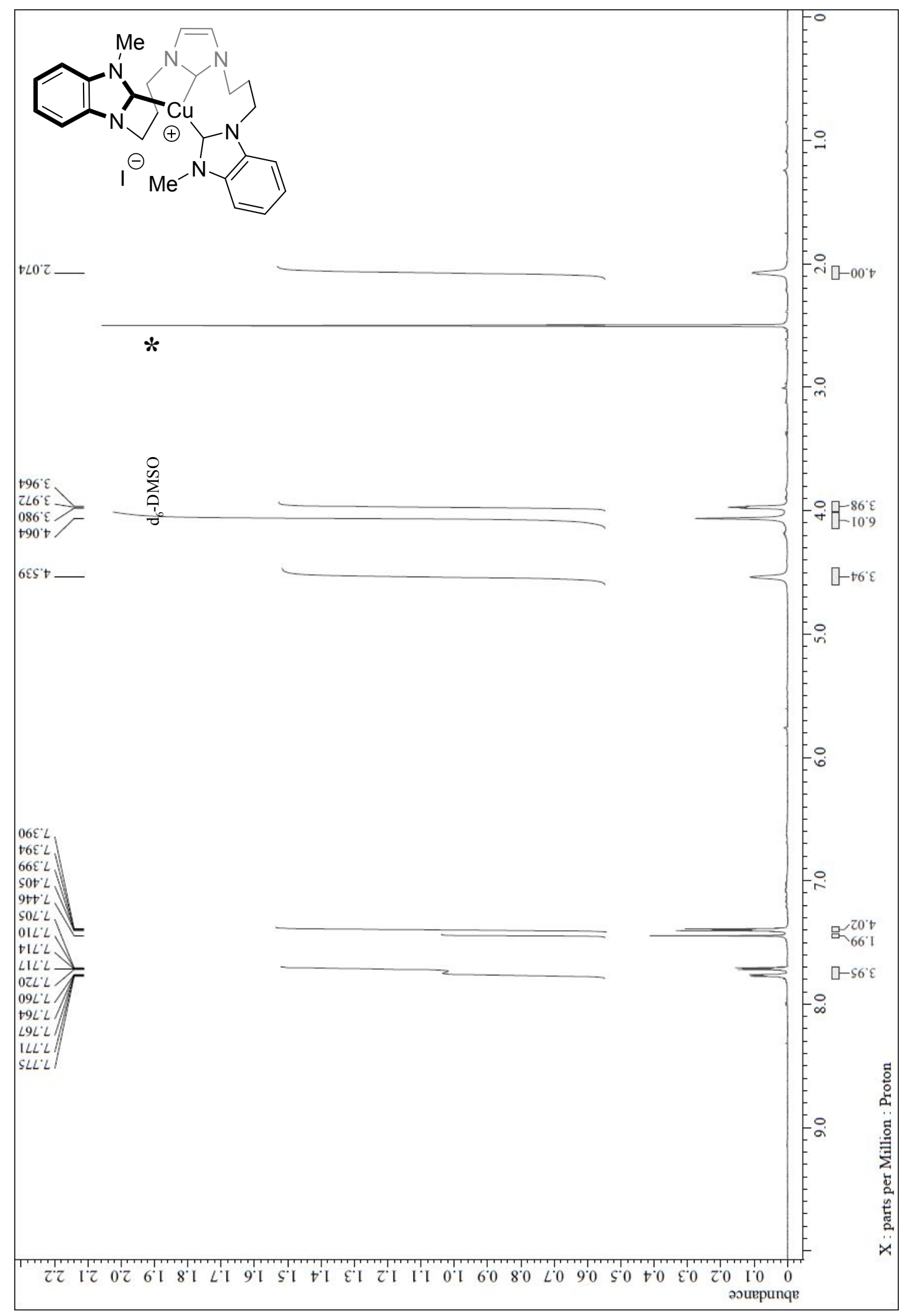


${ }^{13} \mathrm{C}$ NMR of Complex $\mathbf{C}$

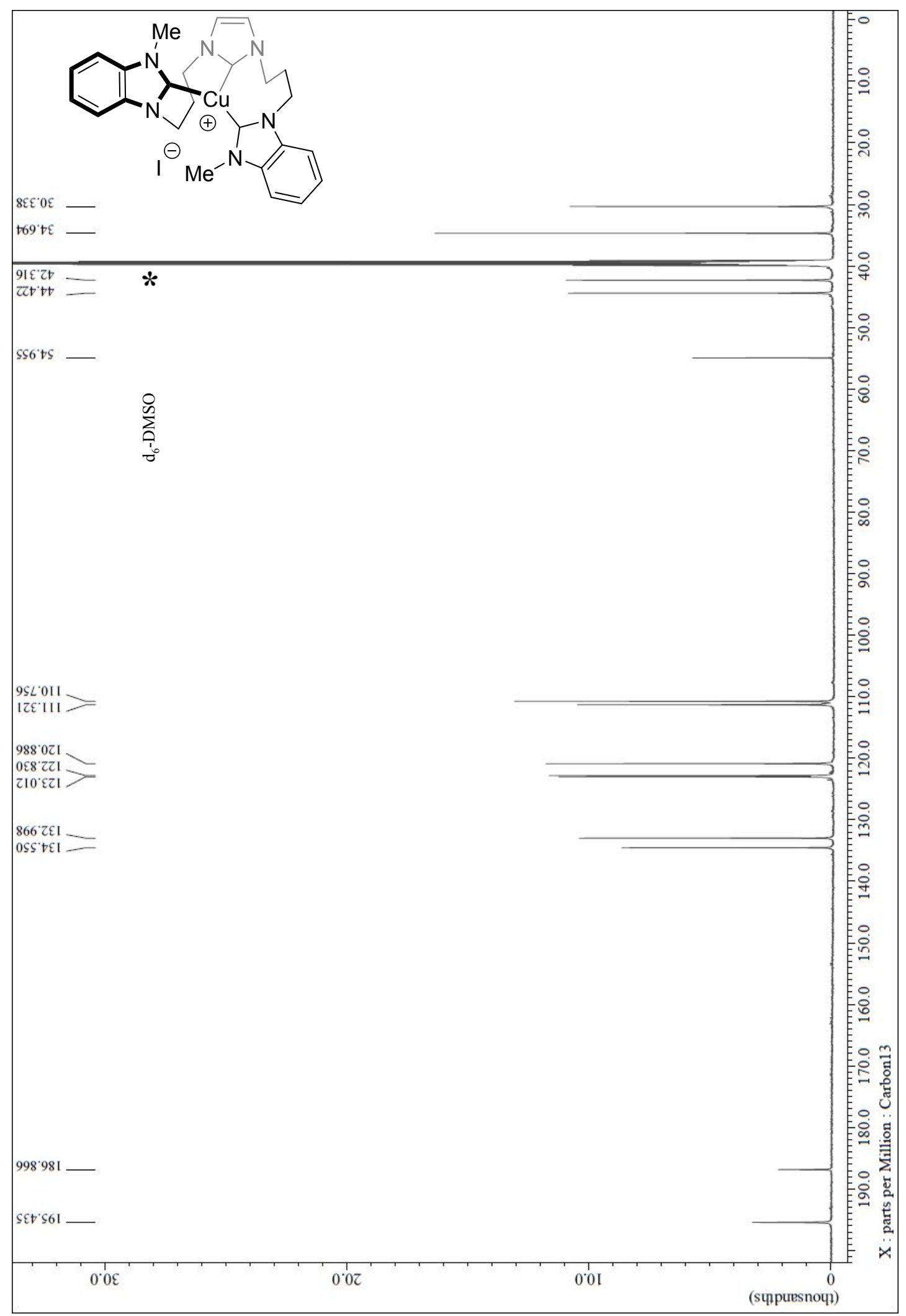


II. NMR spectra of cycloaddition products

${ }^{1} \mathrm{H}$ NMR of 1

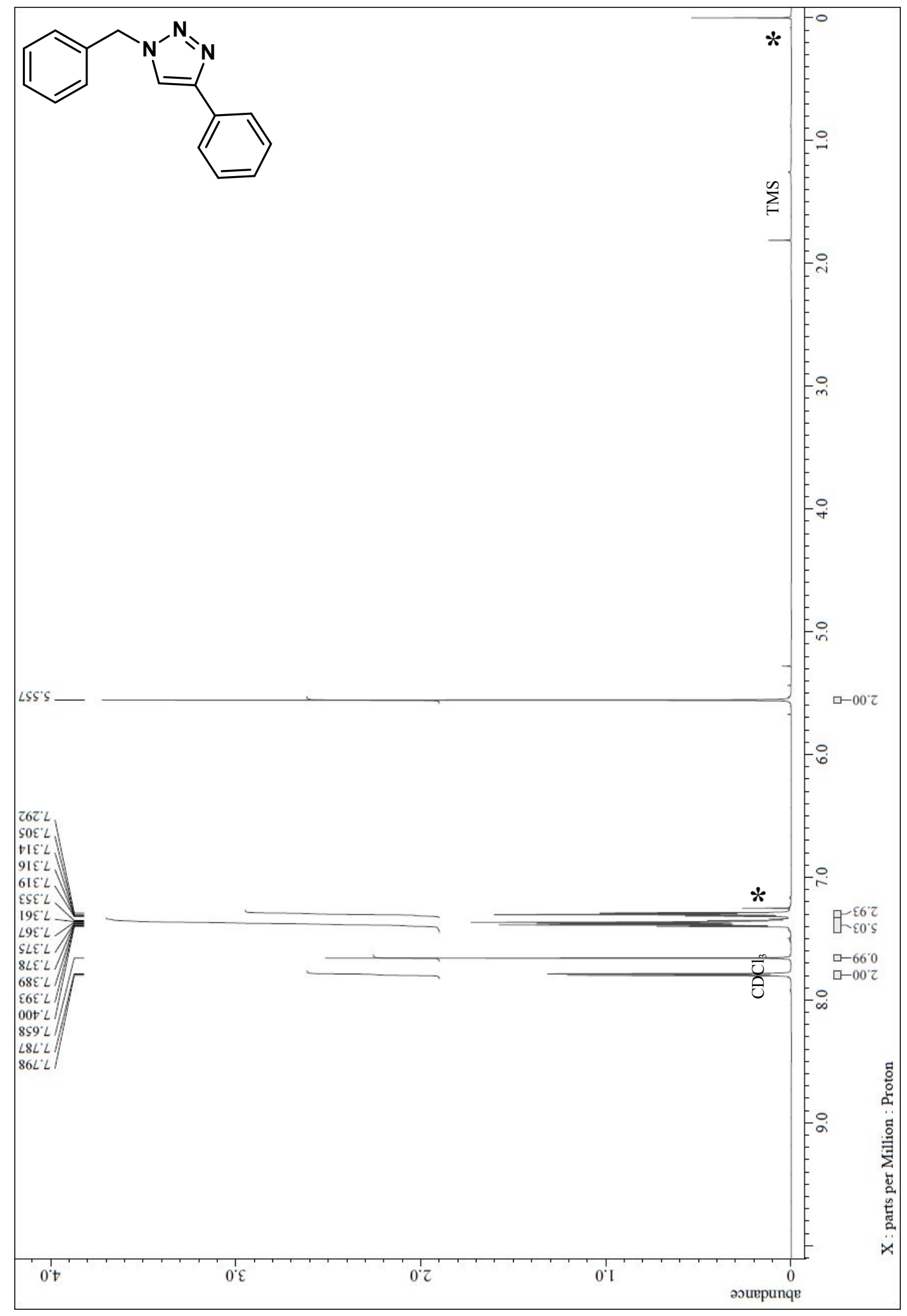


${ }^{13} \mathrm{C}$ NMR of 1

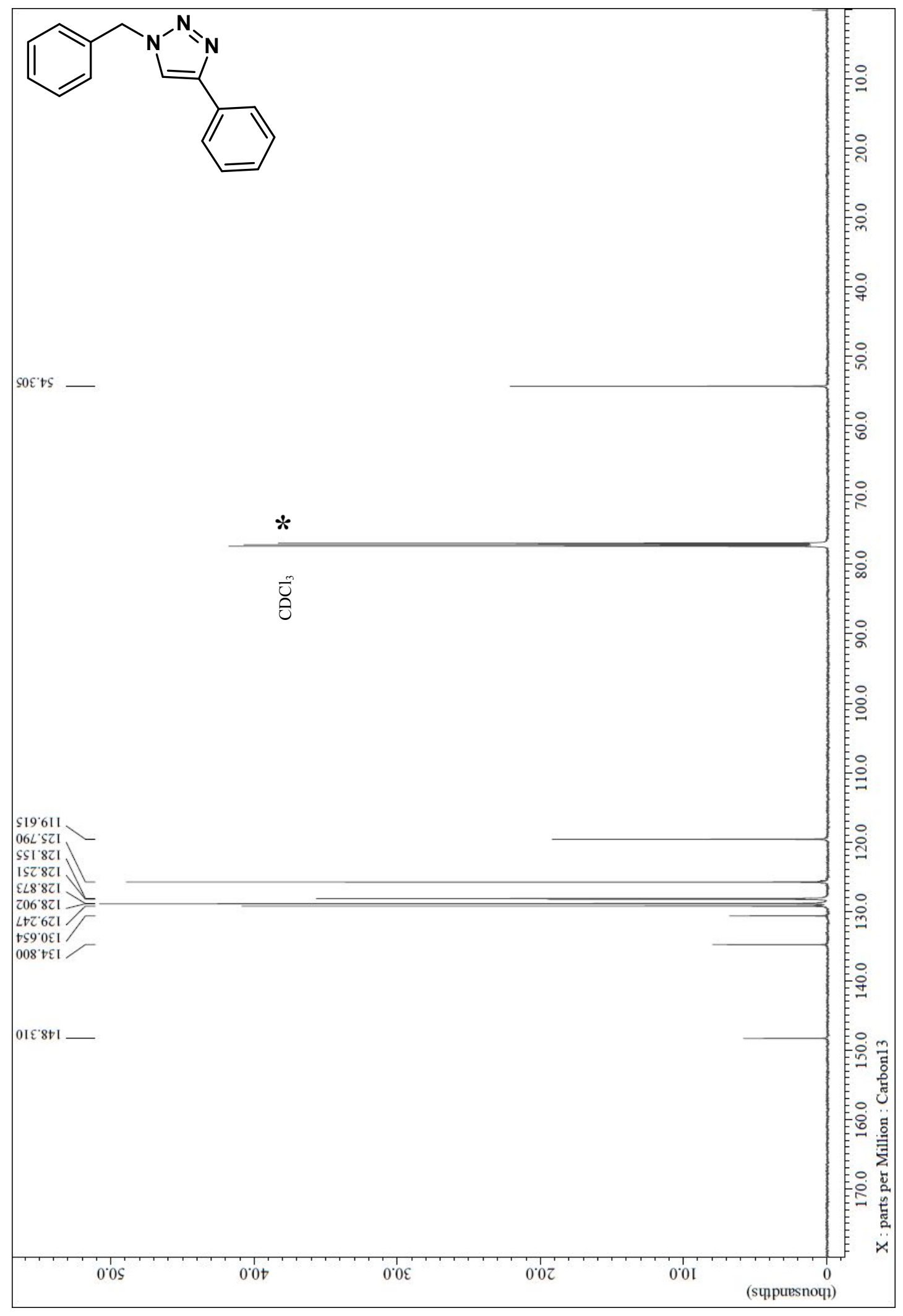


${ }^{1} \mathrm{H}$ NMR of 2

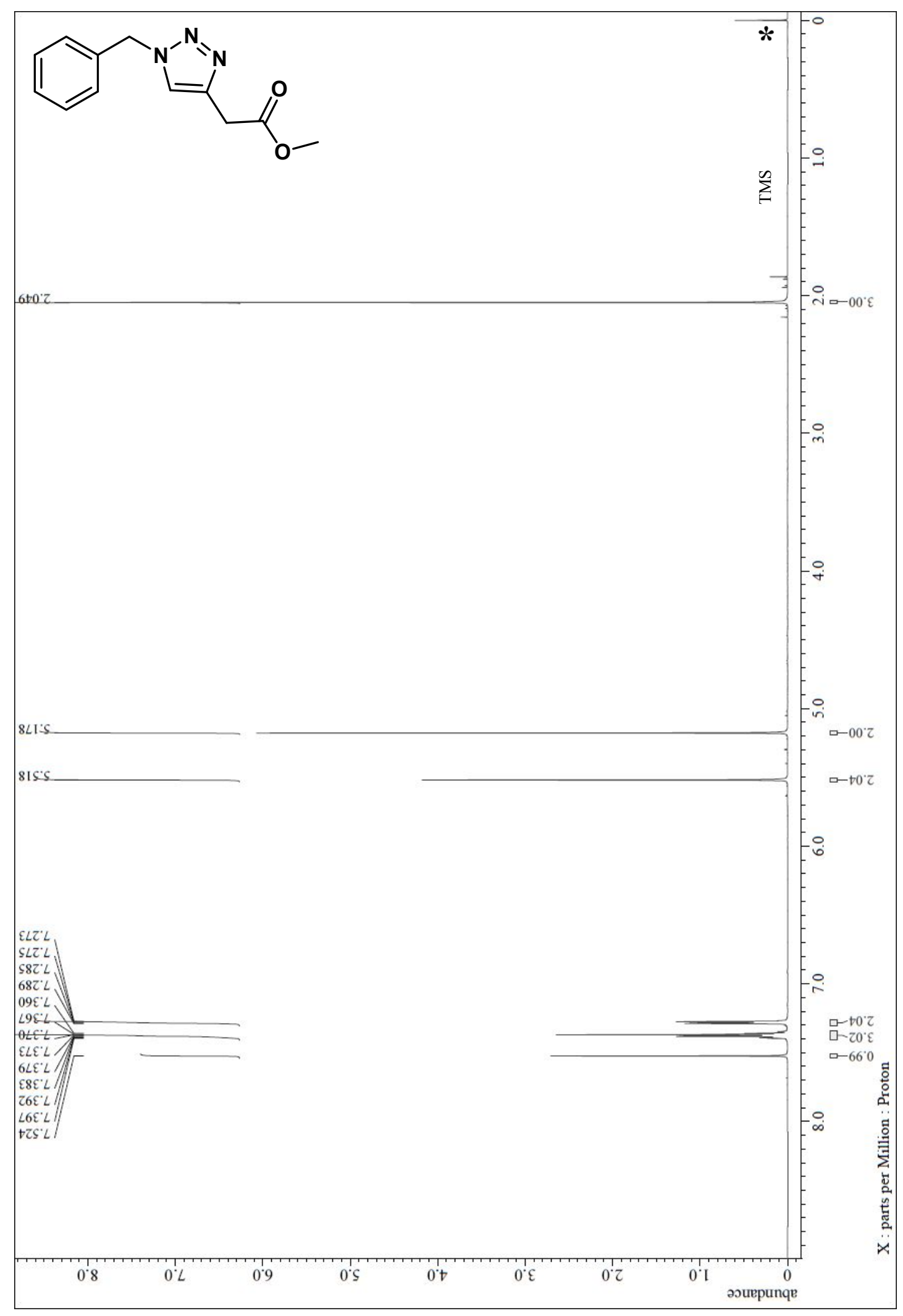


${ }^{13} \mathrm{C}$ NMR of 2

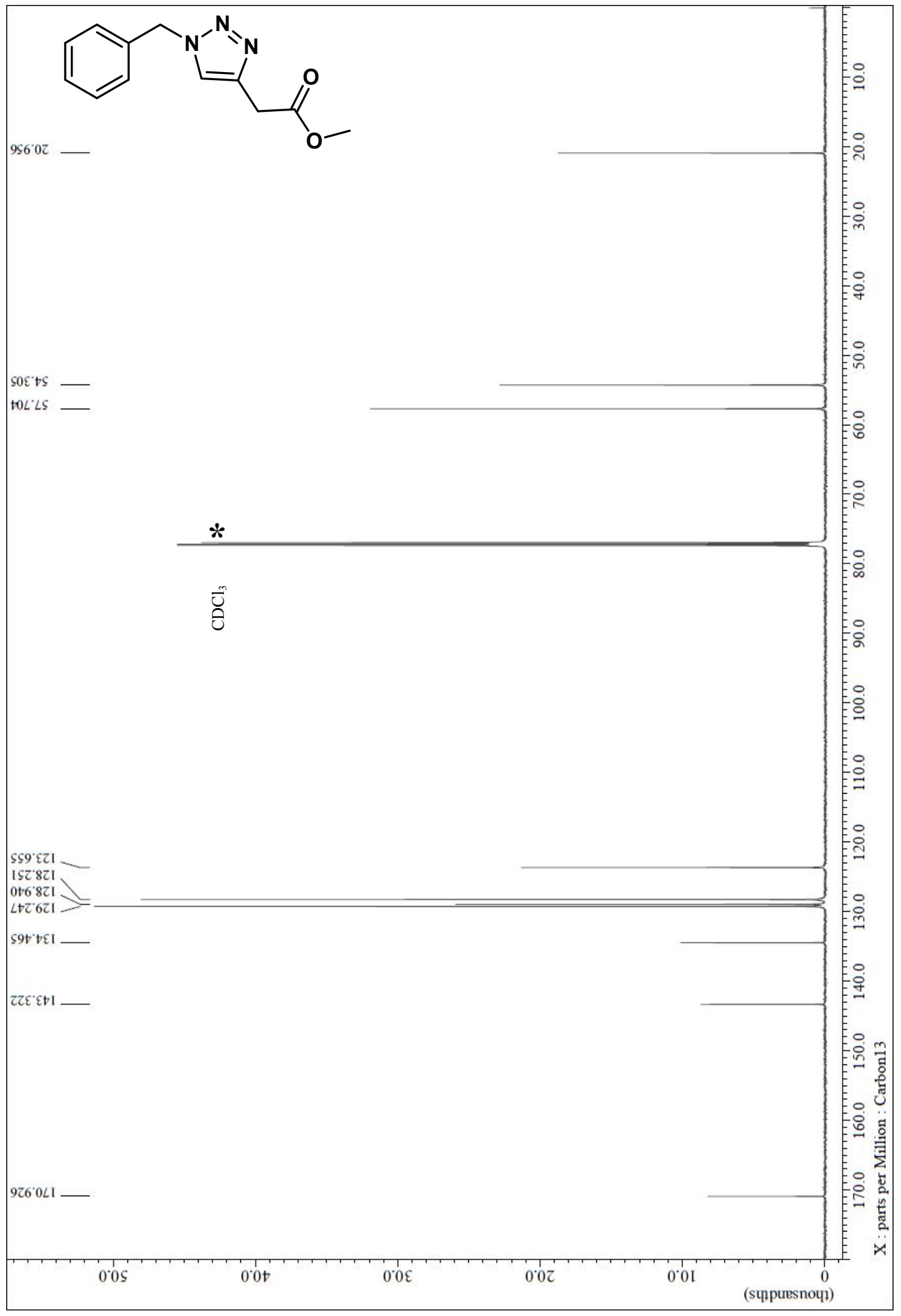


${ }^{1} \mathrm{H}$ NMR of 3

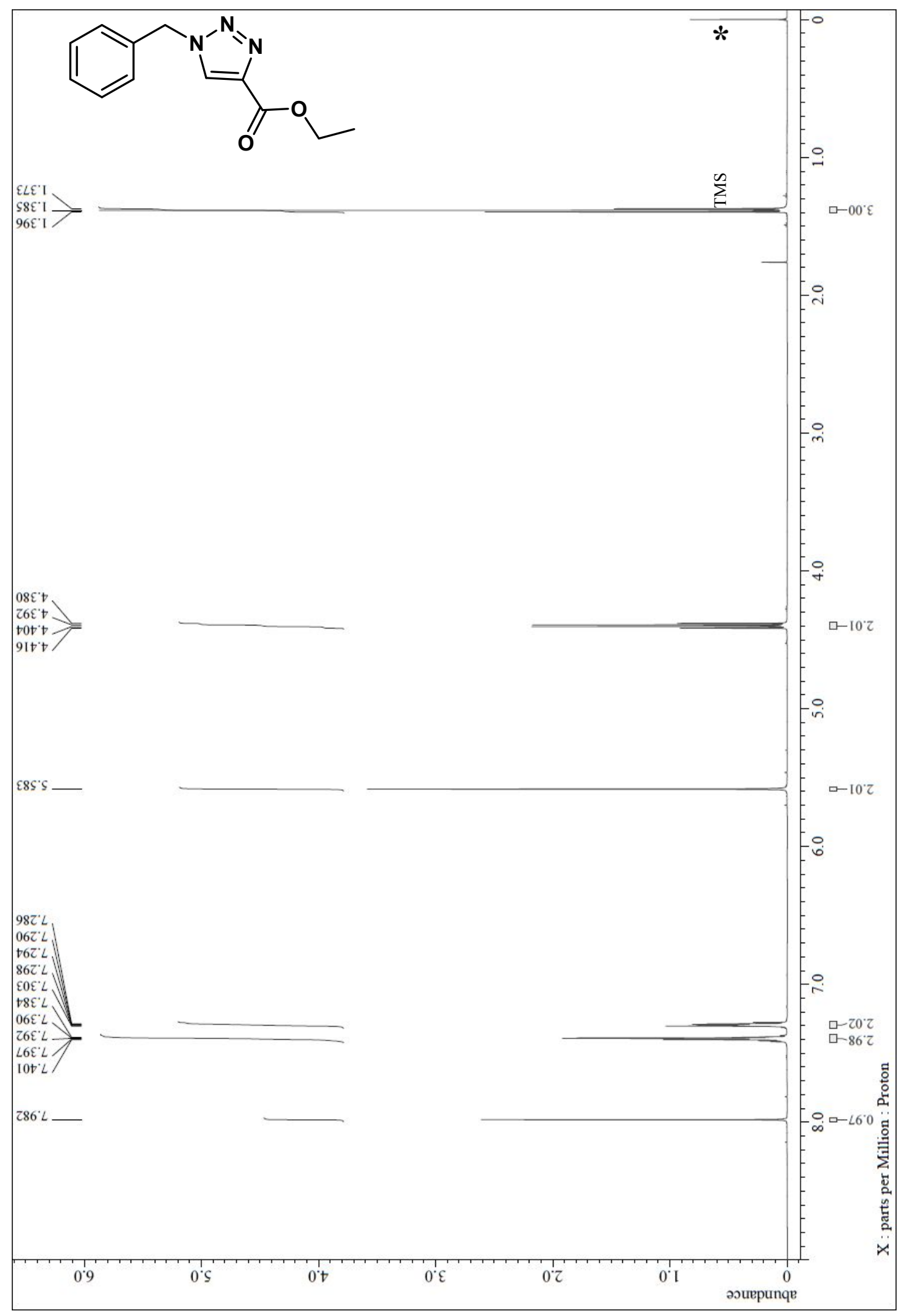


${ }^{13} \mathrm{C}$ NMR of 3

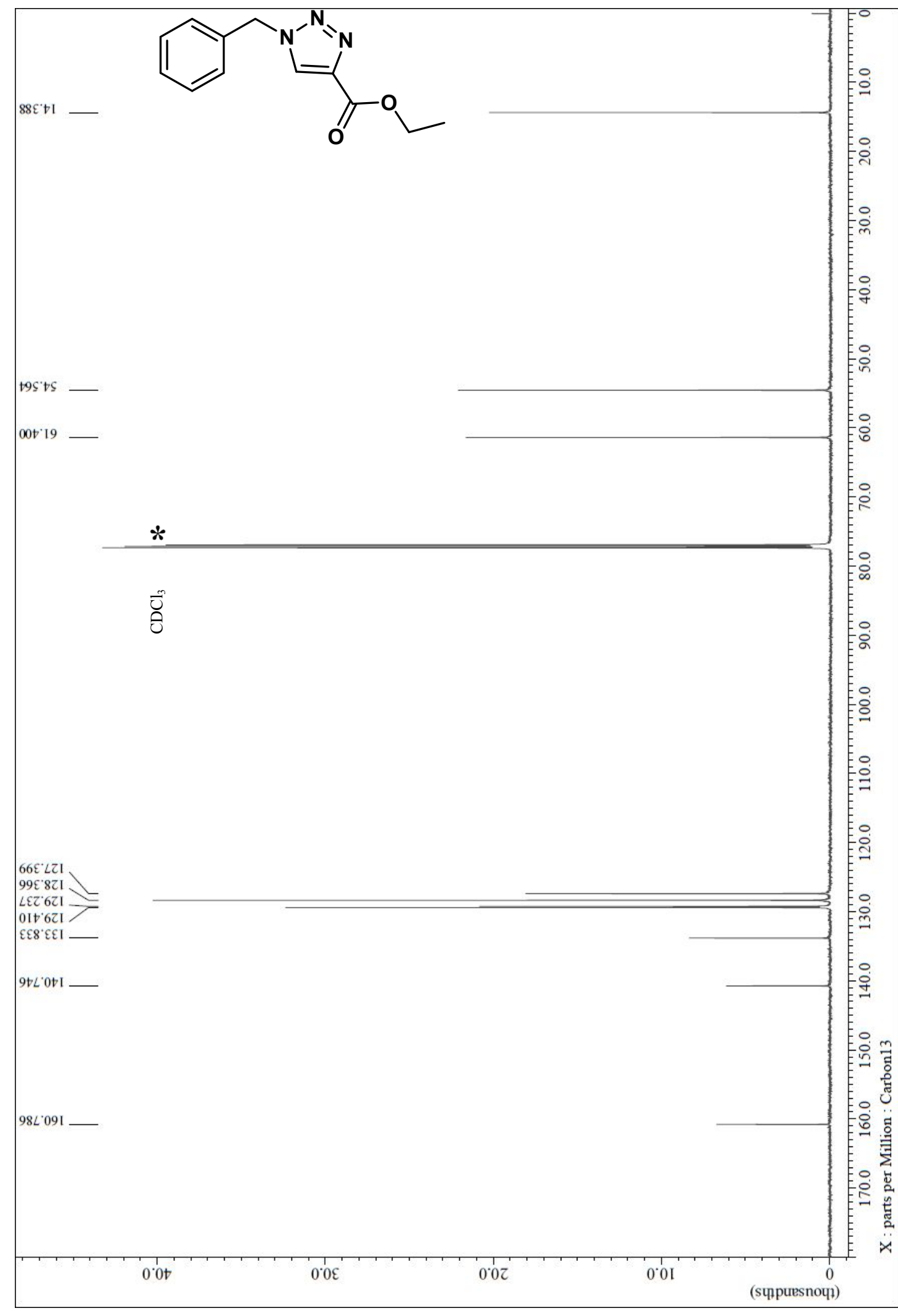


${ }^{1} \mathrm{H}$ NMR of 4

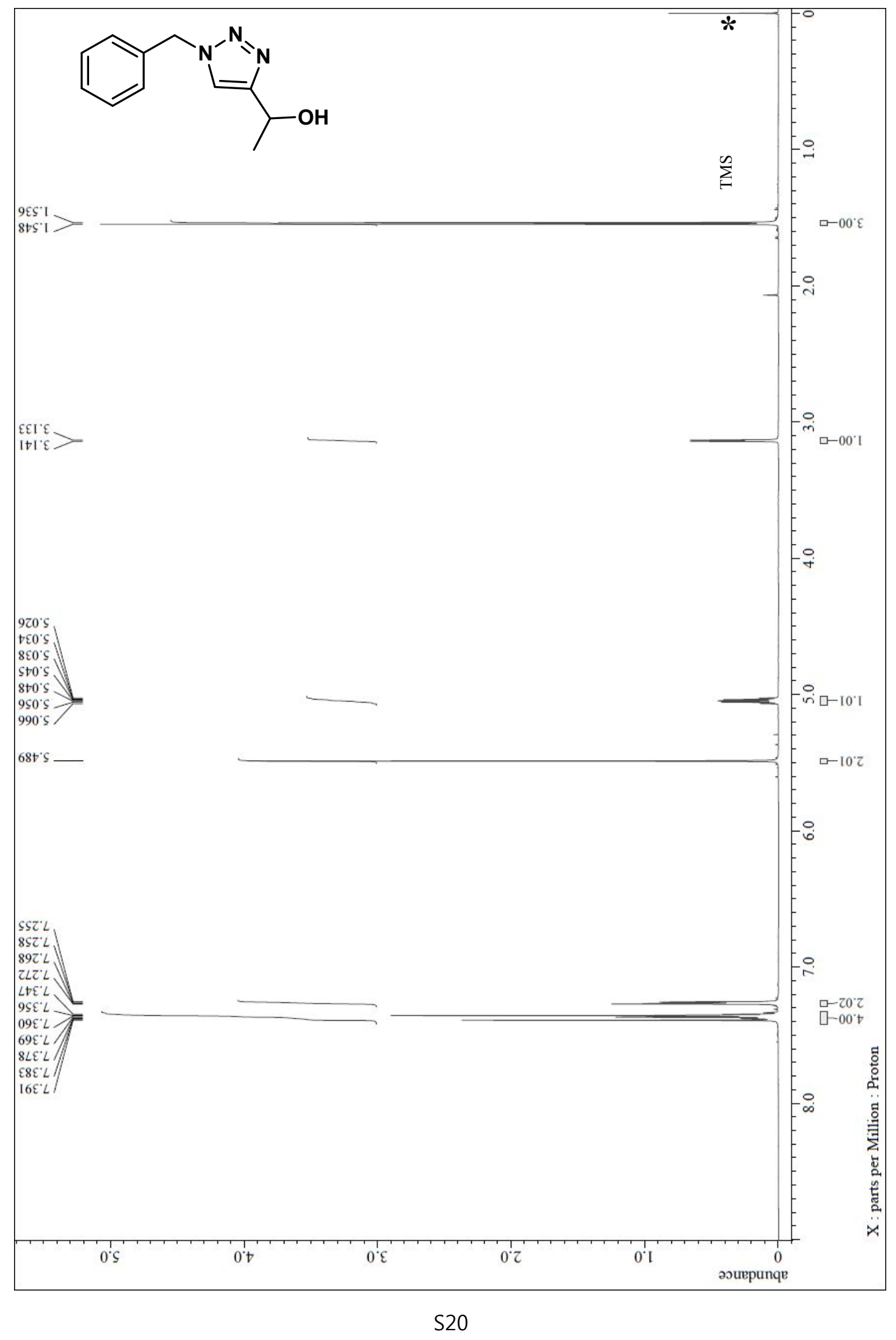


${ }^{13} \mathrm{C}$ NMR of 4

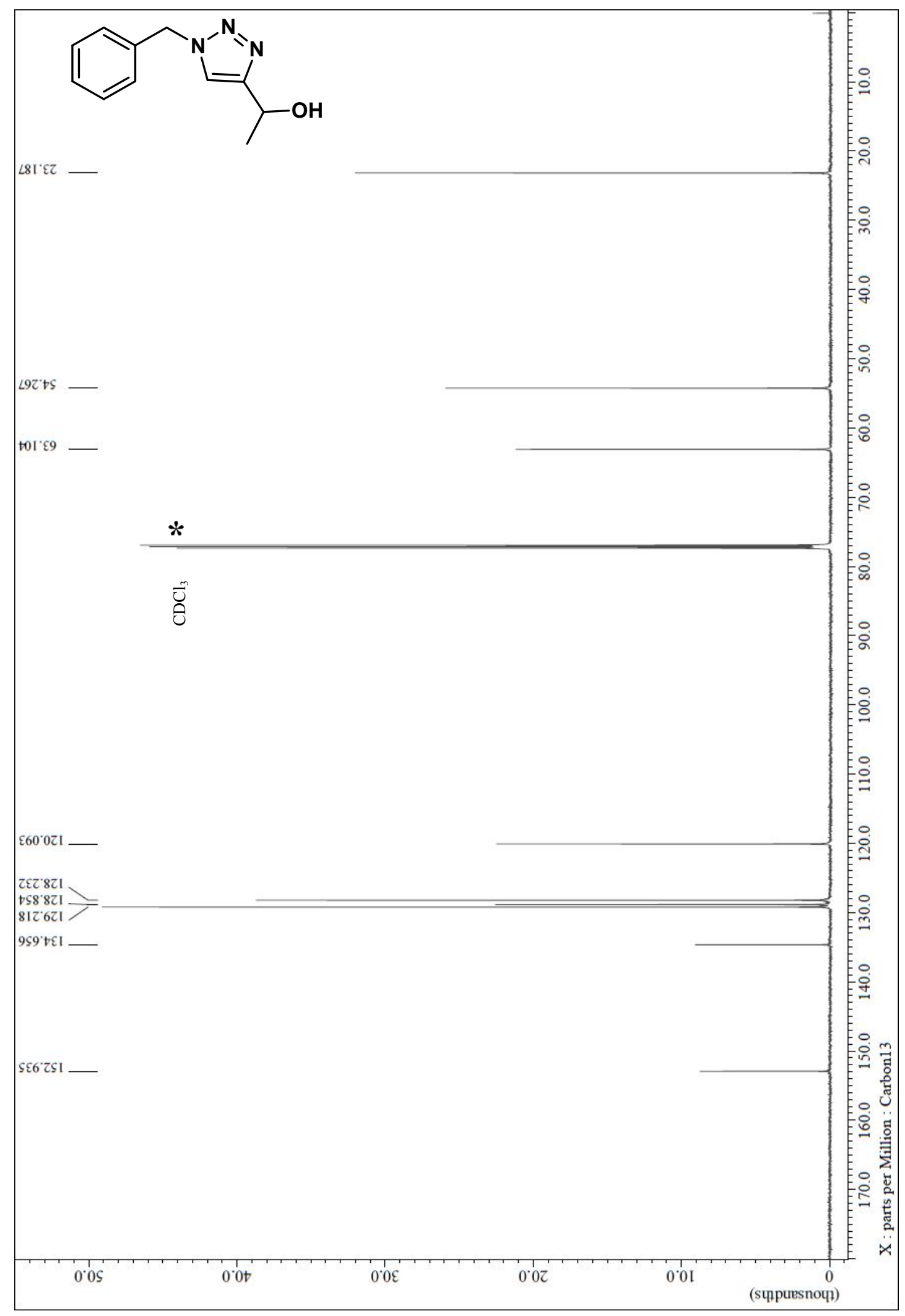


${ }^{1} \mathrm{H}$ NMR of 5

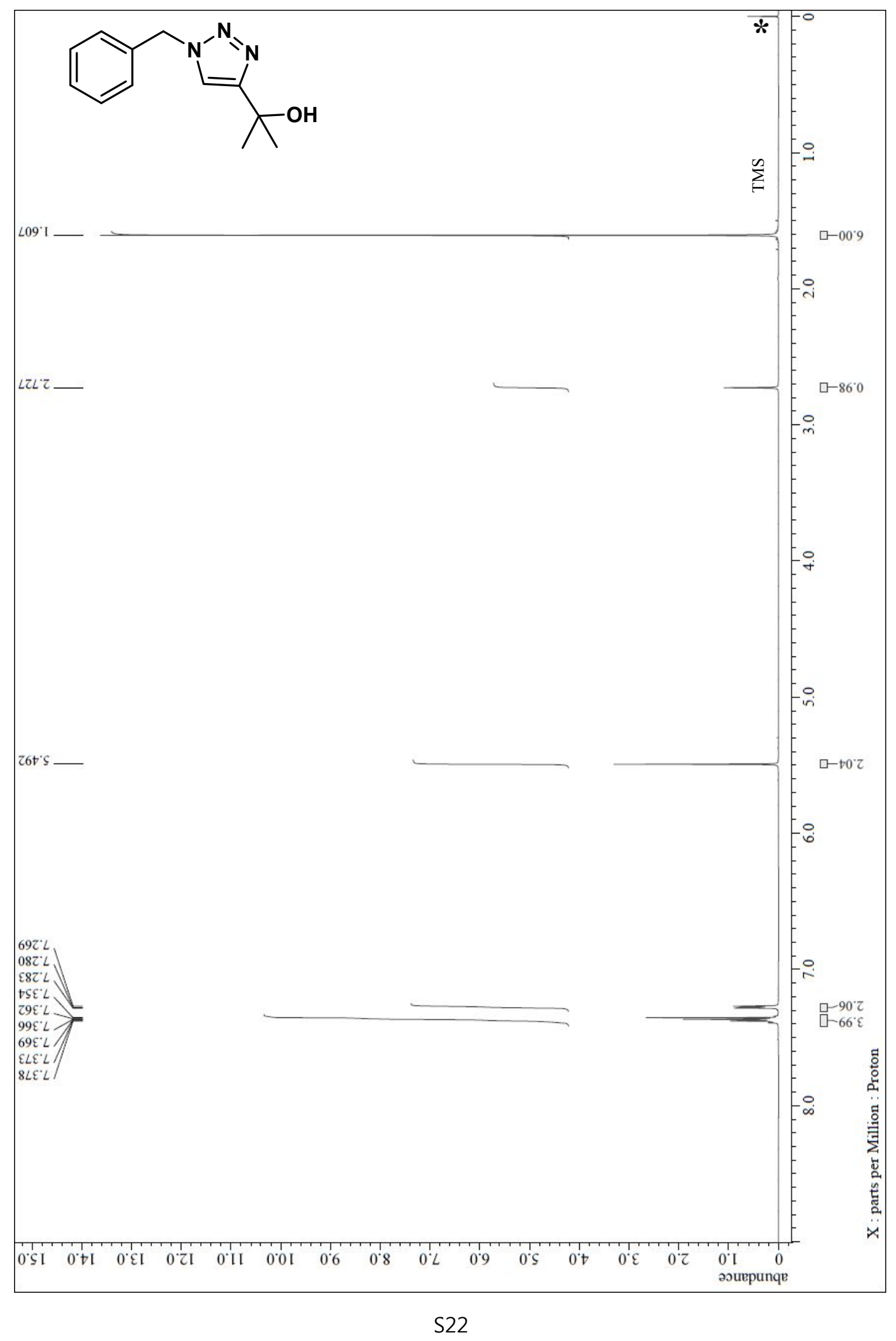


${ }^{13} \mathrm{C}$ NMR of 5

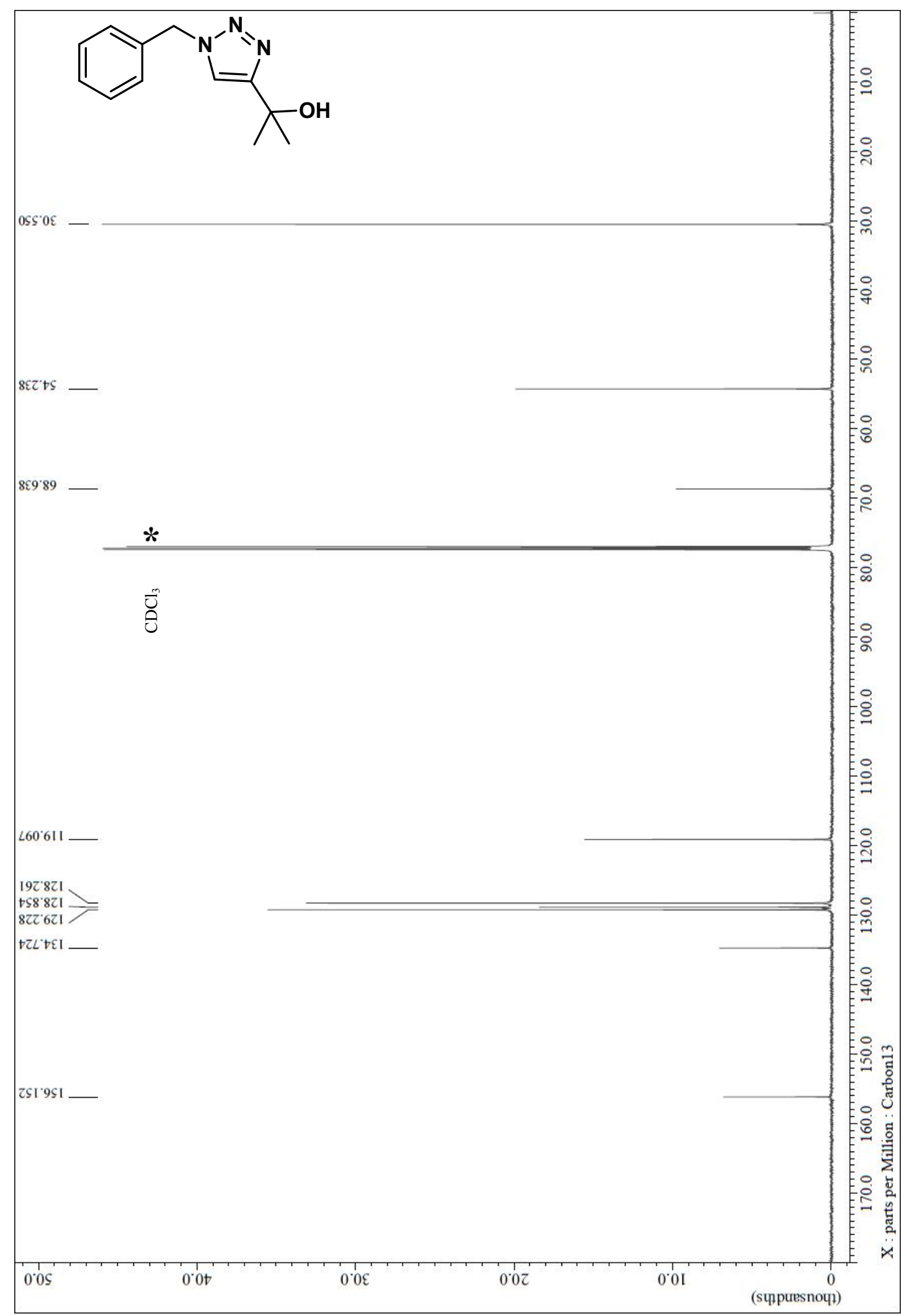


${ }^{1} \mathrm{H}$ NMR of 6

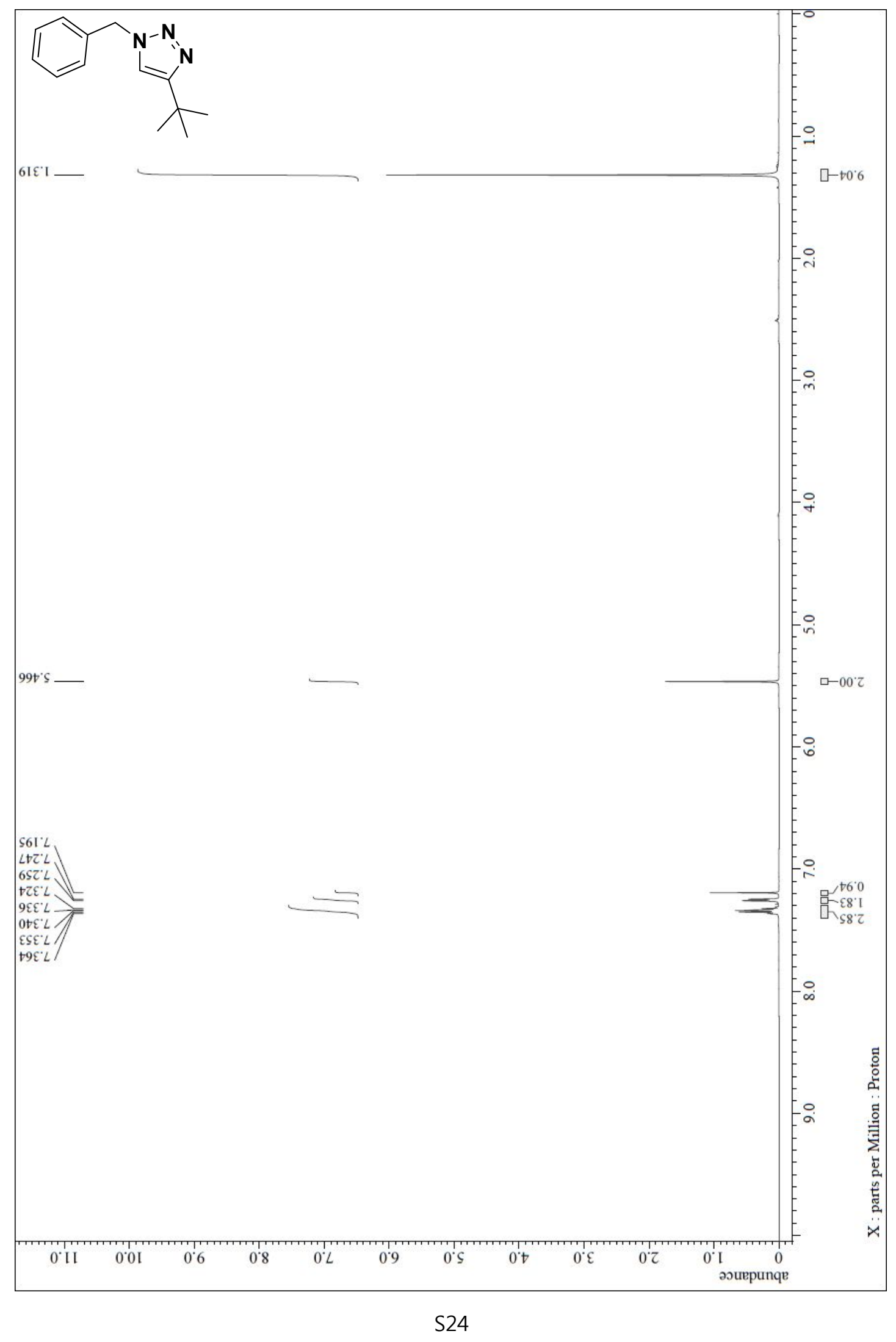


${ }^{13} \mathrm{C}$ NMR of 6

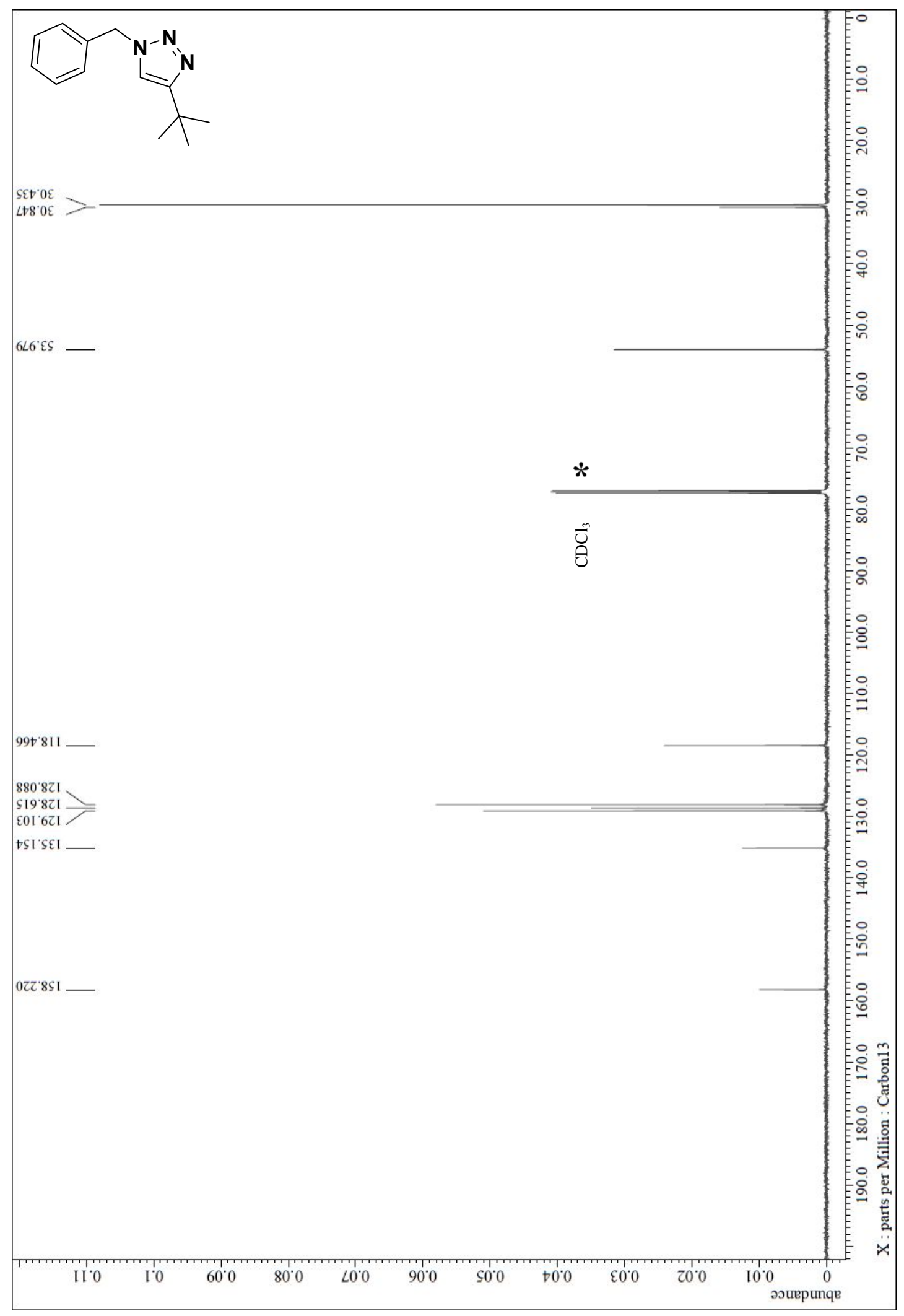


${ }^{1} \mathrm{H}$ NMR of 7

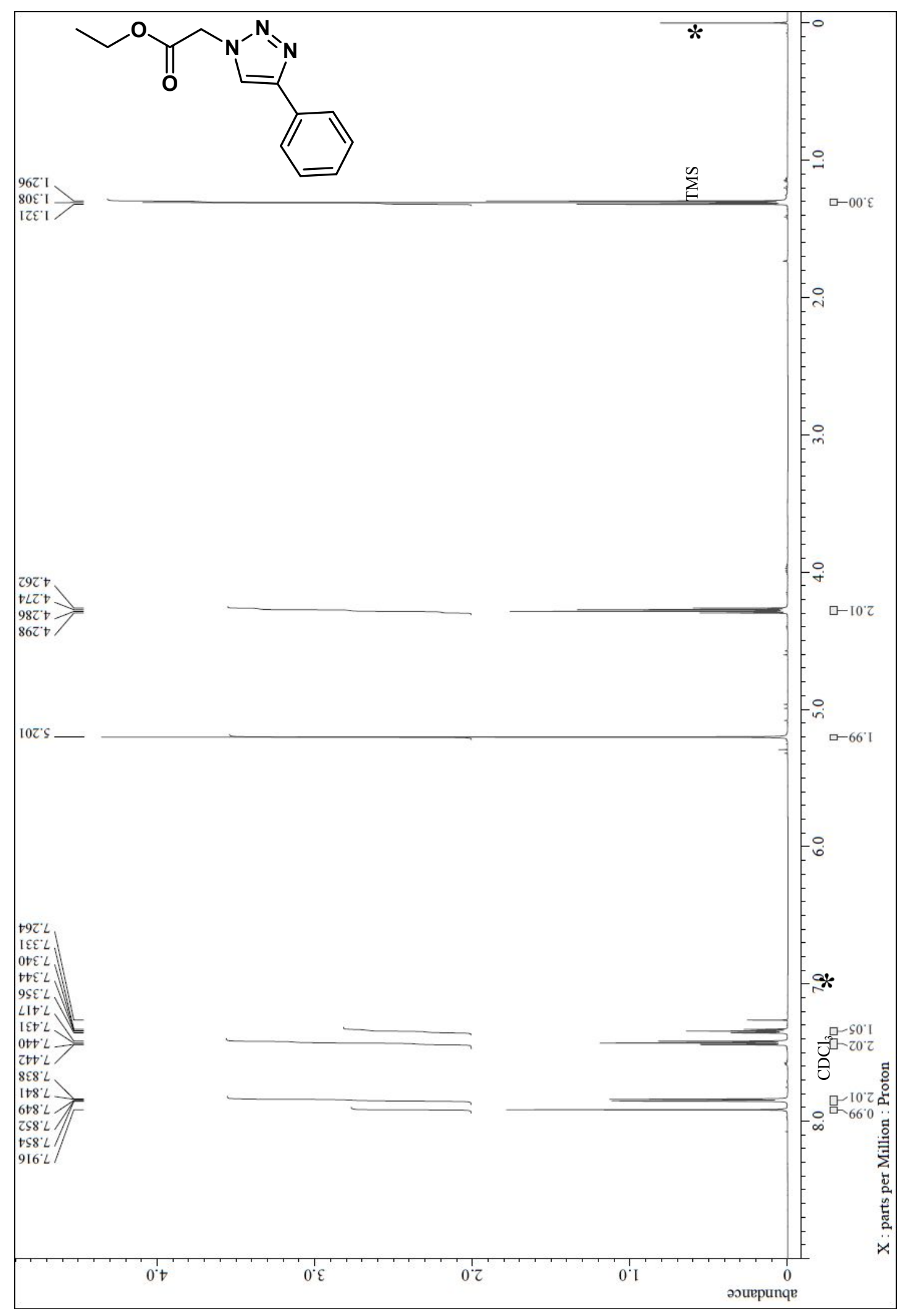


${ }^{13} \mathrm{C}$ NMR of 7

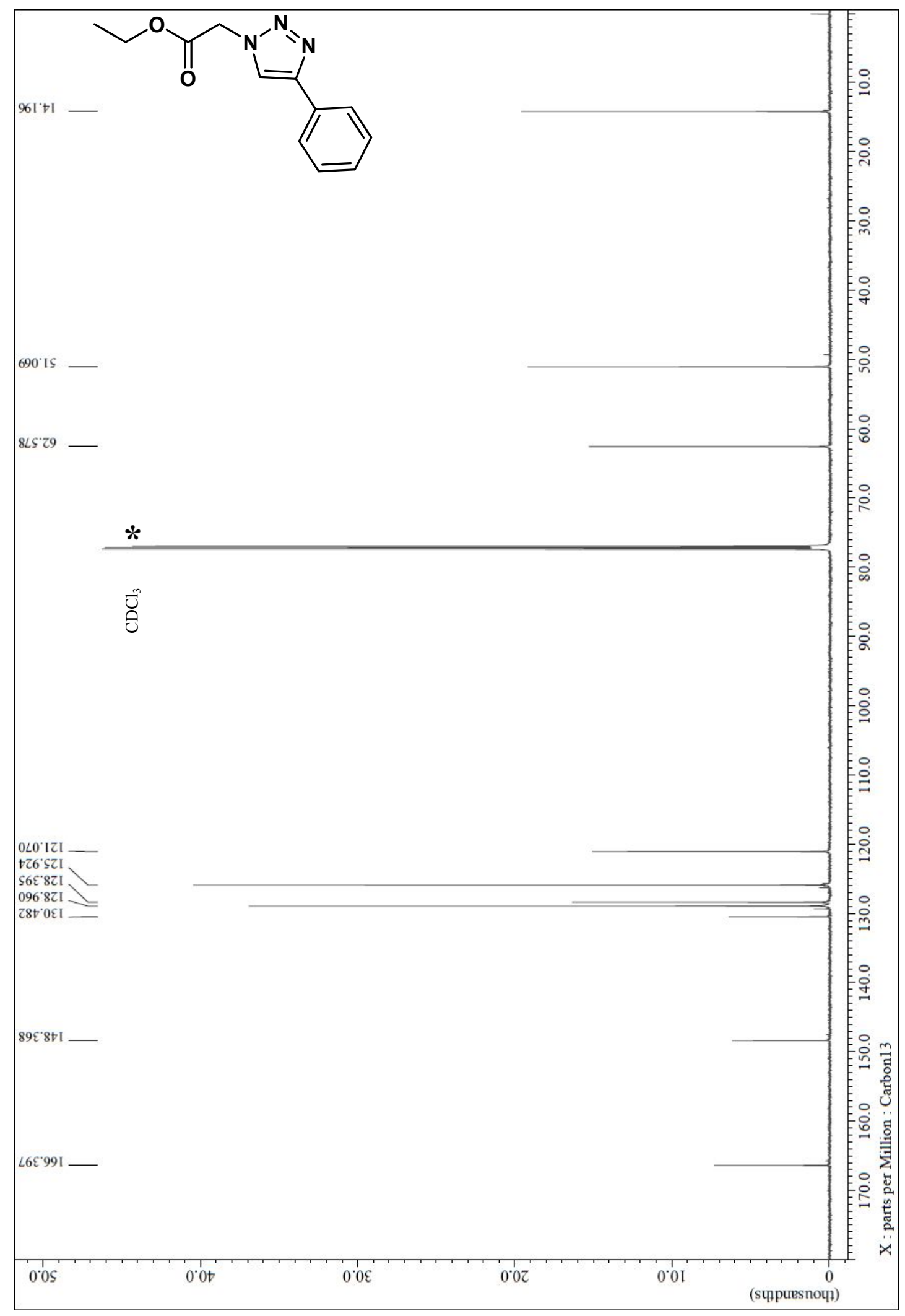


${ }^{1} \mathrm{H}$ NMR of 8

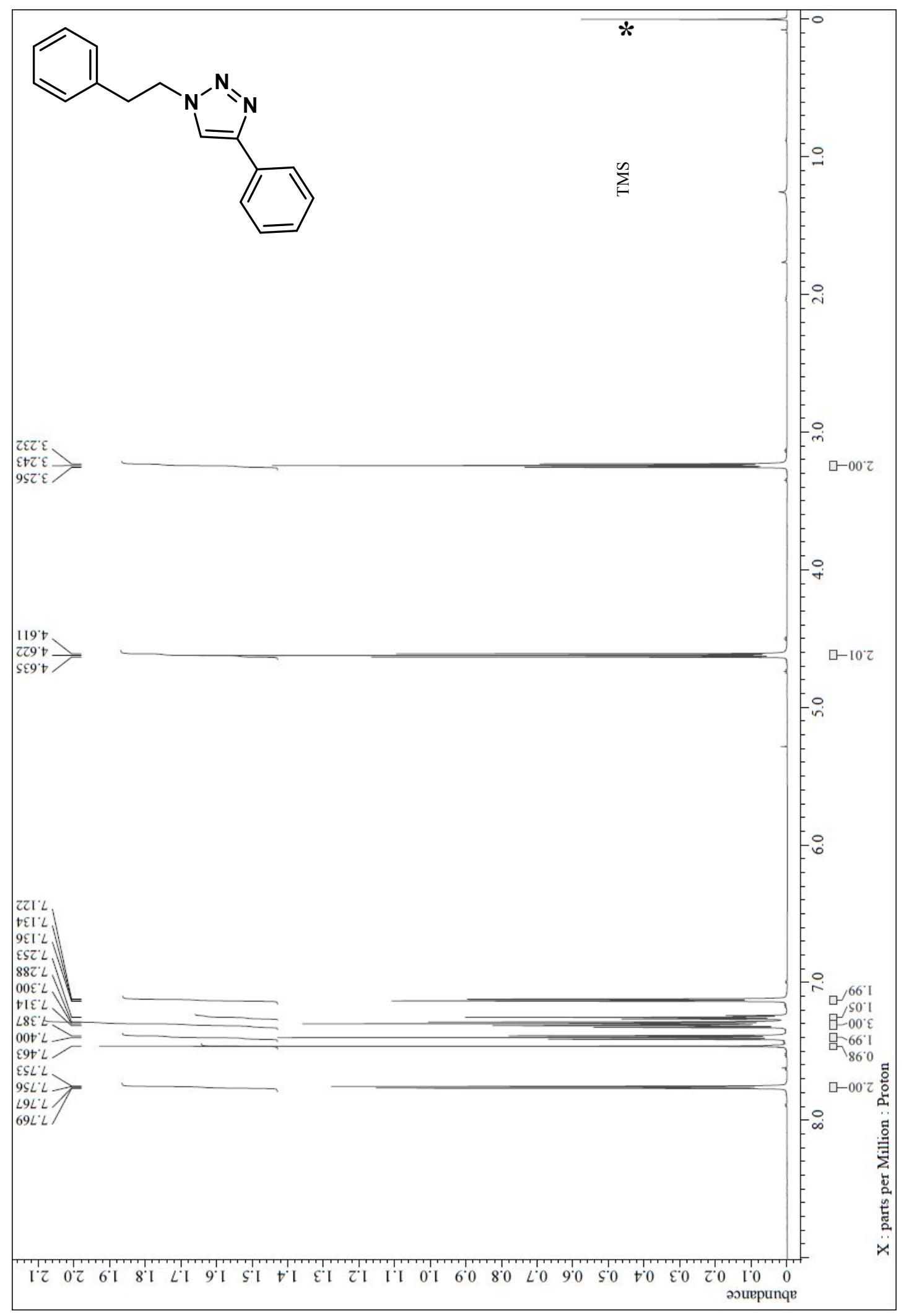


${ }^{13} \mathrm{C}$ NMR of 8

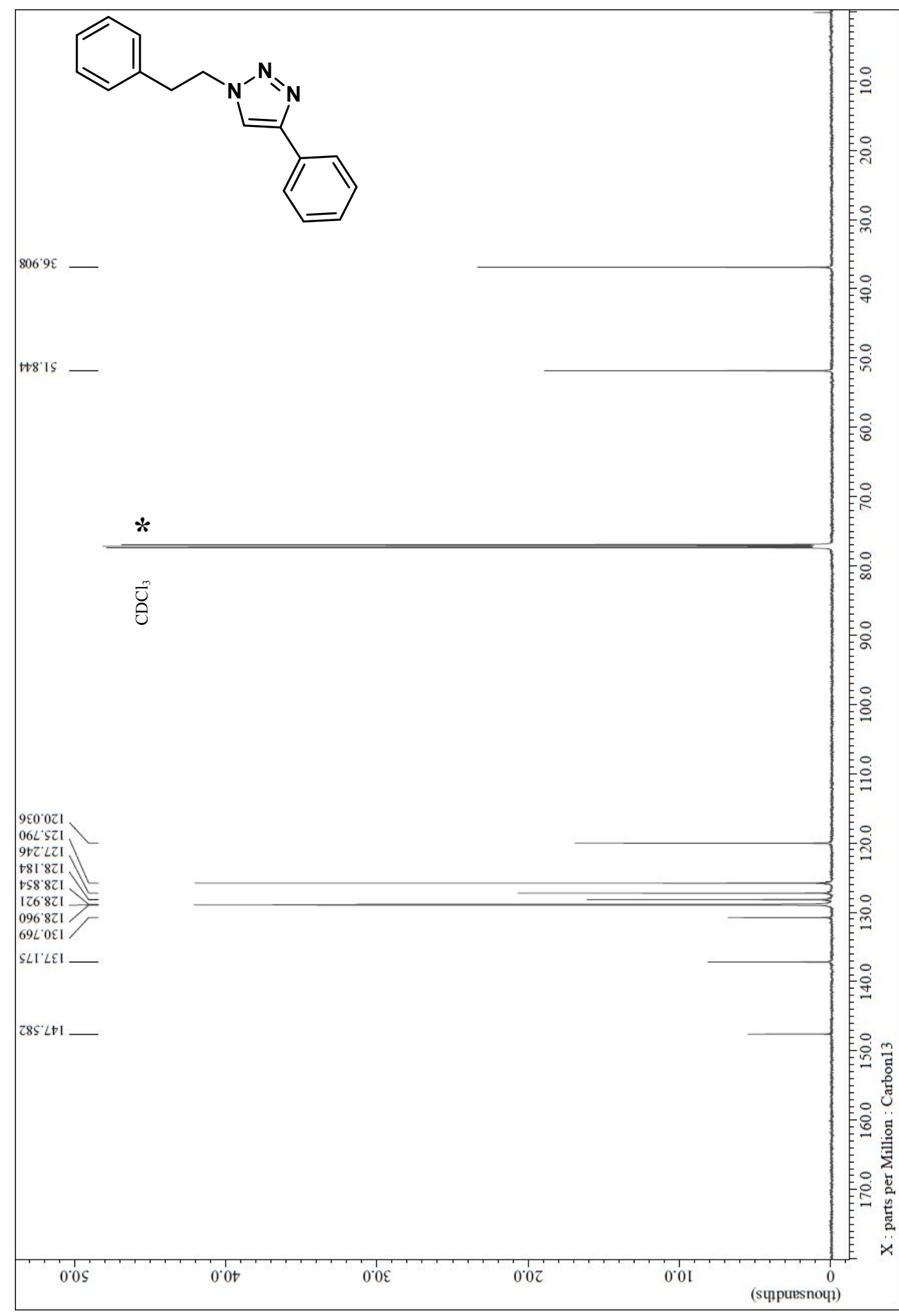


${ }^{1} \mathrm{H}$ NMR of 9

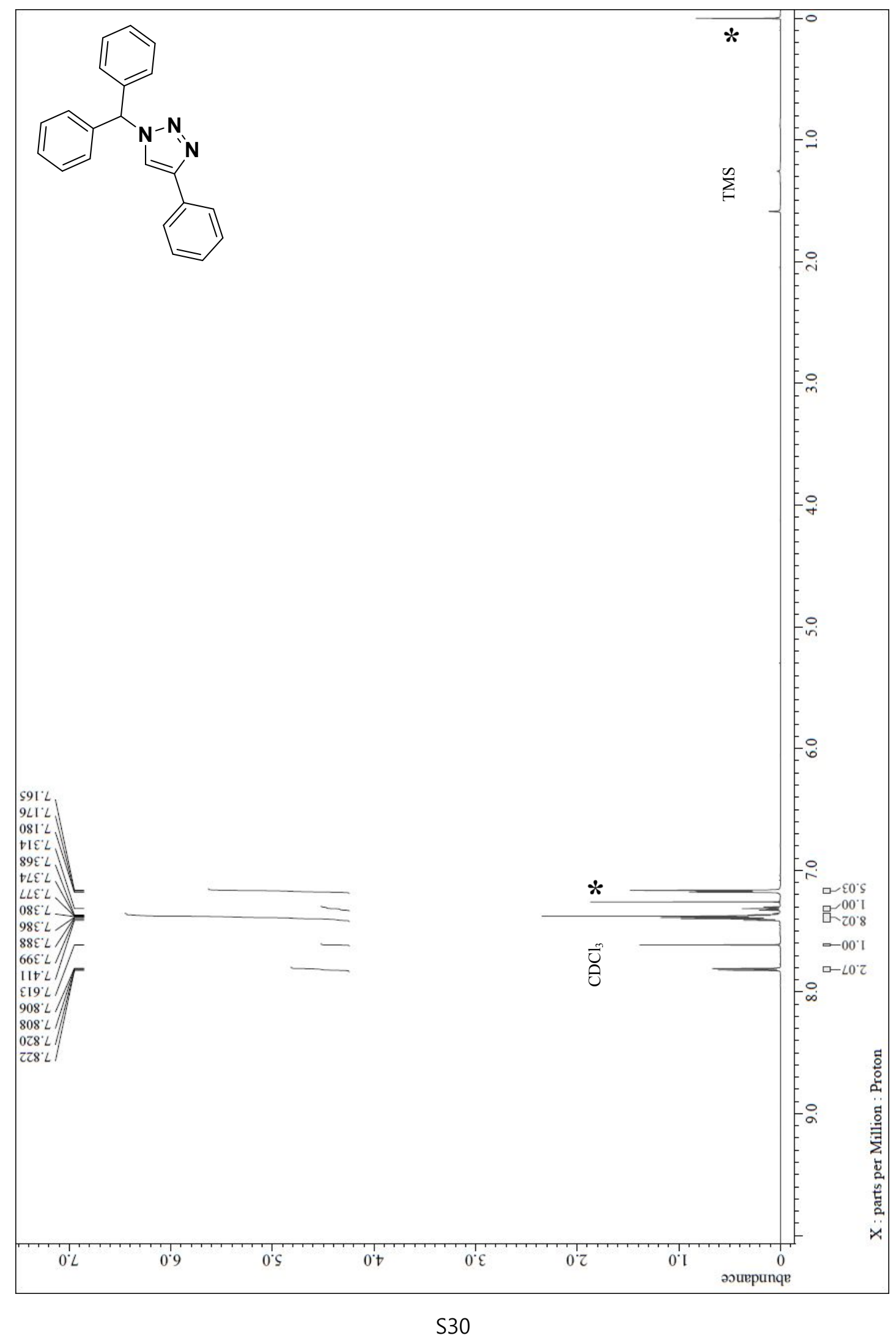


${ }^{13} \mathrm{C}$ NMR of 9

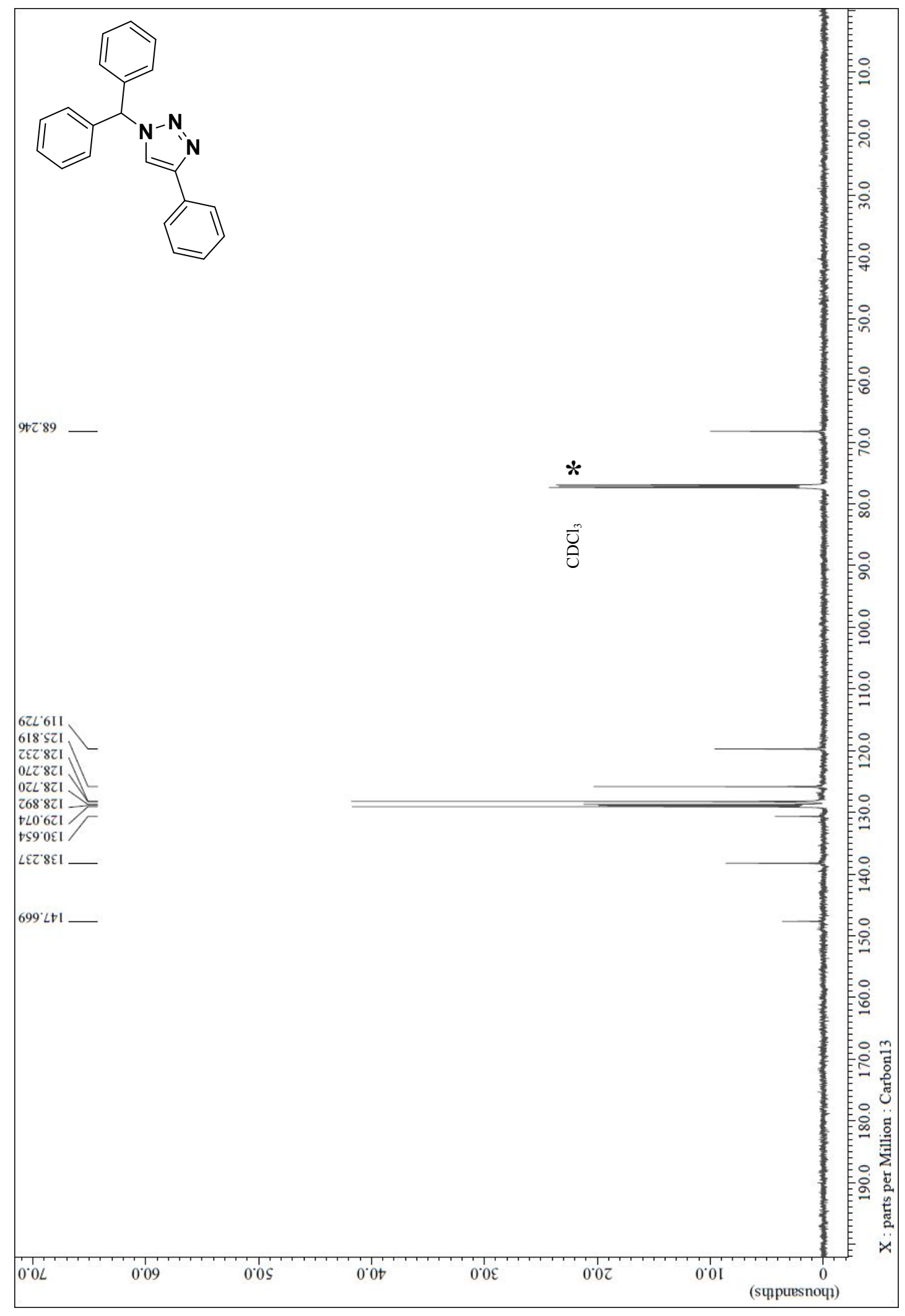




\section{EXAFS analysis}

The data analysis for the $\mathrm{Cu}$ K-edge EXAFS was performed by a typical procedure as reported previously. ${ }^{1,2}$ All the present spectra were first normalized by fitting the smooth EXAFS high-energy region with linear function after subtracting the background extrapolated from the pre-edge region. The resulting spectra, $\mu(E)$, were normalized to an edge jump of unity in order to compare the XANES features directly with one another. The absorption spectrum for the isolated atom, $\mu_{0}(E)$, was approximated by a cubic spline. The EXAFS functions, $\chi(E)$, obtained from the equation, $\chi(E)=\left\{\mu(E)-\mu_{0}(E)\right\} / \mu_{0}(E)$, were Fourier transformed. The resulting $\chi(k)$ oscillations were weighted by $k^{3}$ to compensate for the attenuation of the EXAFS in the high- $k$ region and were Fourier transformed in the range of $3 \leq k \leq 13 \AA^{-1}$ with a Hanning apodization function. In order to determine the structural parameters, a non-linear least-squares curve fitting procedure was carried out for the first shell corresponding to the $\mathrm{Cu}-\mathrm{C}$ bonds and the second shell including the $\mathrm{Cu}-\mathrm{N}$ pairs by using the EXAFS formula according to the following EAXFS formula:

$$
\chi(k)=\sum_{l} \frac{S_{o}^{2} N_{l}}{k R_{l}^{2}} F_{l}(k) \exp \left(-2 \sigma_{l}^{2} k^{2}\right) \exp \left(\frac{-2 R_{l}}{\lambda(k)}\right) \sin \left\{2 k R_{l}+\phi(k)\right\}
$$

The back scattering amplitude, $F_{l}(k)$, the total phase shift, $\phi(k)$, and the photoelectron mean free path, $\lambda(k)$, were theoretically calculated for all the scattering paths by the curved wave ab initio FEFF program. The amplitude reduction factor $\left(S_{0}\right)$, the interatomic distance $\left(R_{l}\right)$, Debye-Waller factor $\left(\sigma^{2}\right)$, and threshold energy difference $\left(\Delta E_{\mathrm{o}}\right)$ were set as variables and the coordination number, $N_{l}$, for was set equal to the crystallographic values in the fitting procedure. The input parameter $R_{\mathrm{bkg}}$ that determines the maximum frequency of the background was set to $1.2 \AA$. In the fitting procedure, we have used first four scattering paths, $\mathrm{Cu}-\mathrm{C}_{1}, \mathrm{Cu}-\mathrm{C}_{2}, \mathrm{Cu}-$ $\mathrm{N}_{1}$ and $\mathrm{Cu}-\mathrm{N}_{2}$ in the range $R \leq 3.0 \AA$ obtained from FEFF calculations. All parameters iteratively refined. The first and second peaks in the FT correspond to the nearest and next-nearest neighbors of the copper ion, which are the $\mathrm{Cu}-\mathrm{C}$ and $\mathrm{Cu}-\mathrm{N}$ shells, respectively

(1) Teo, B. K. EXAFS: Basic Principles and Data Analysis, Springer-Verlag, Berlin, 1986.

(2) Kim, S. J.; Lemaux, S.; Demazeau, G.; Kim, J. Y.; Choy, J. H. X-Ray absorption spectroscopic study on LaPdO3 J. Mater. Chem. 2002, 12, 995-1000. 
Table S1. The EXAFS fitting results (coordination number, interatomic distance, and Debye-Waller factor) for $\mathbf{A}, \mathbf{B}$ and $\mathbf{C}$. The interatomic distances determined from single-crystal XRD analysis of $\mathbf{A}$ are also presented for comparison.

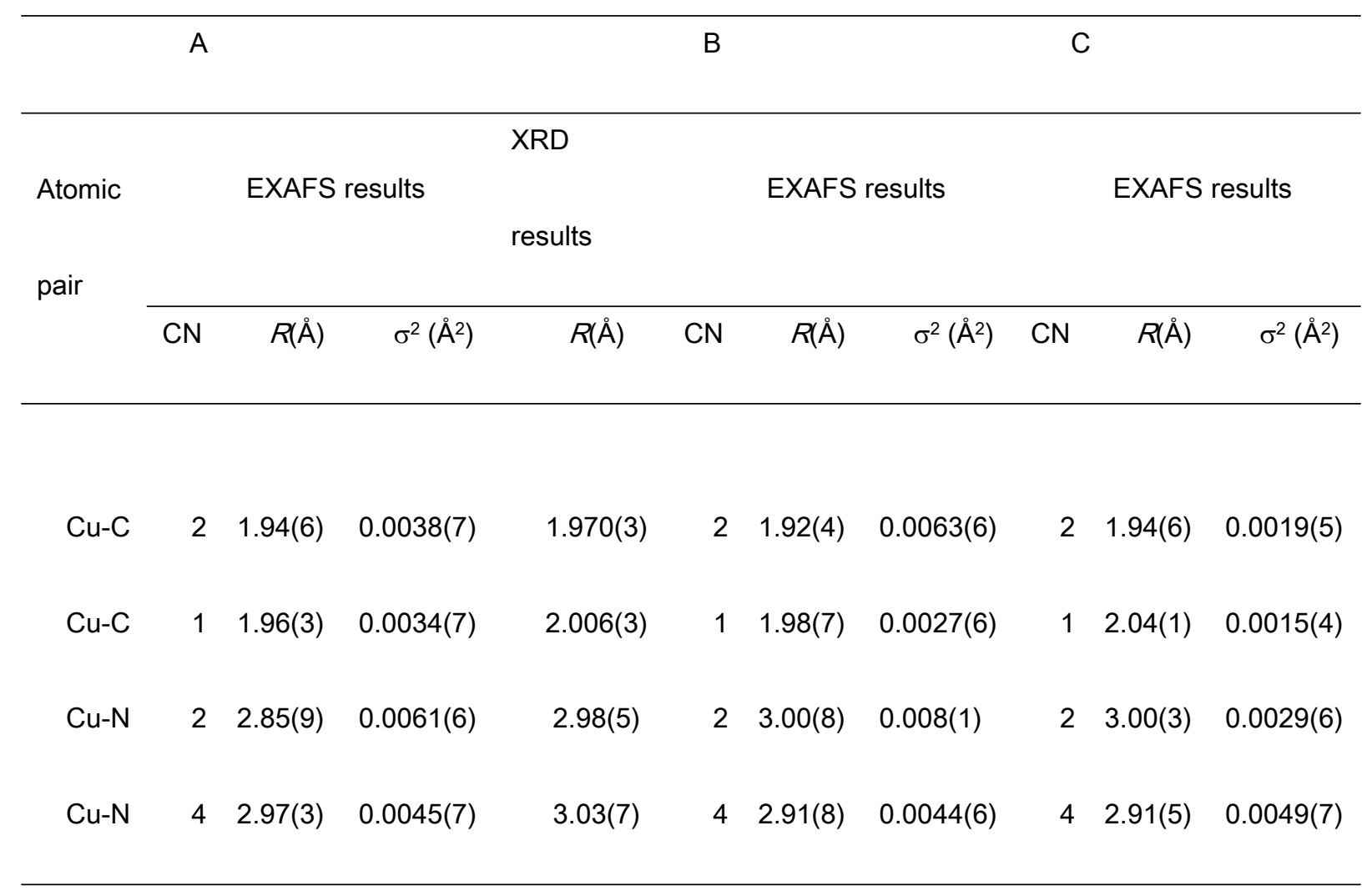



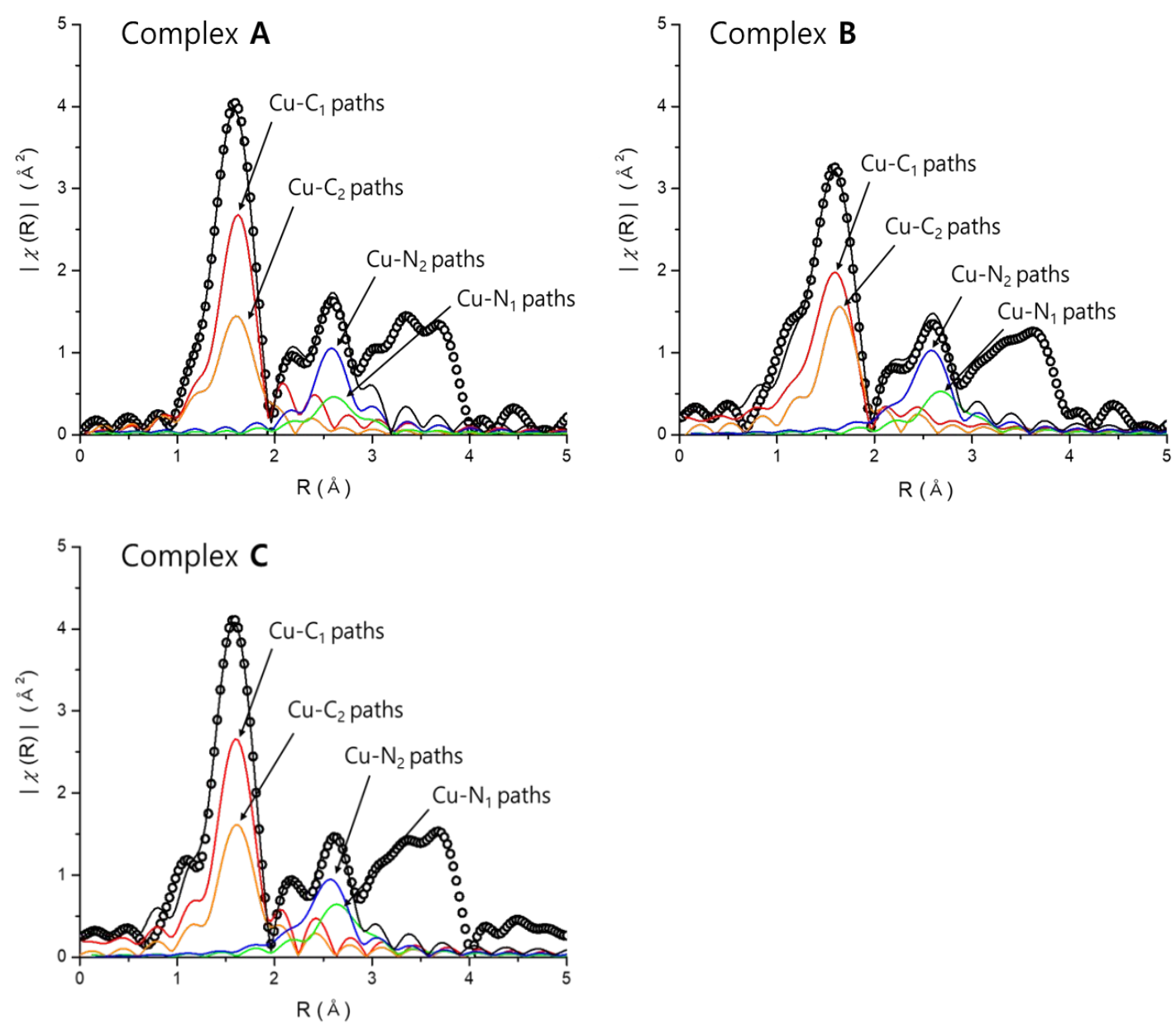

Figure S1. Theoretically calculated contributions to $\chi(R)$ by the single scattering paths $\mathrm{Cu}-\mathrm{C}_{1}, \mathrm{Cu}-\mathrm{C}_{2}, \mathrm{Cu}-\mathrm{N}_{1}$ and $\mathrm{Cu}-\mathrm{N}_{2}$ in the complexes, $\mathbf{A}, \mathbf{B}$, and $\mathbf{C}$. The experimental data and the best-fits are also represented by empty circles and solid lines, respectively. 
IV. Stability test of $\mathrm{Cu}$ complexes by ${ }^{1} \mathrm{H}$ NMR

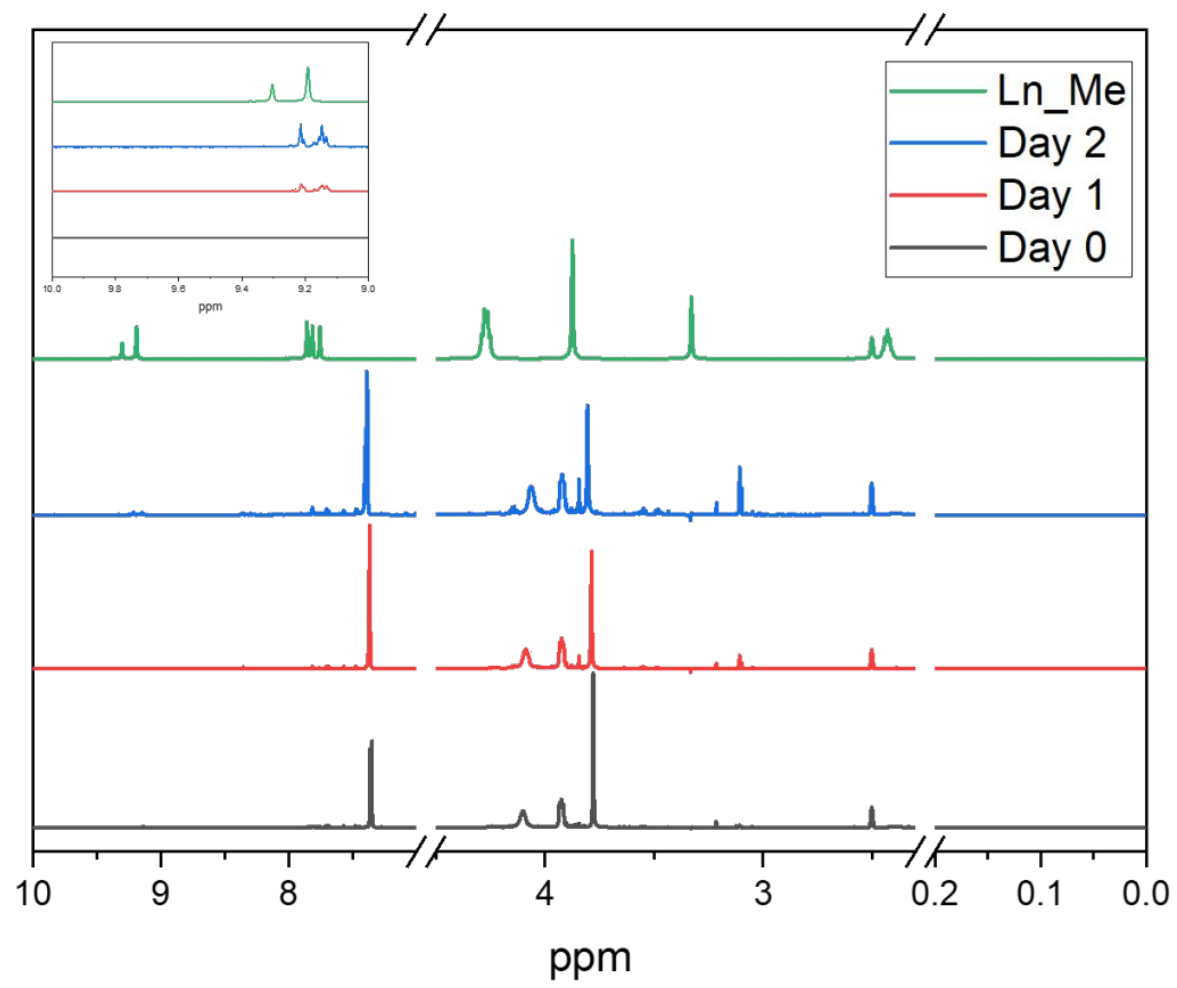

Figure S2. ${ }^{1} \mathrm{H}$ NMR spectra of the ligand $\left(1,1^{\prime}-((1 H\right.$-imidazole-3-ium-1,3-diyl)bis(propane-3,1-diyl))bis(3methyl-1H-imidazol-3-ium) triiodide, Ln_Me) and complex A measured from the solution in $\mathrm{d}_{6}$-DMSO stored at room temperature for 0 to 2 days. The inset graphs are the enlarged spectra between 9 and $10 \mathrm{ppm}$. 


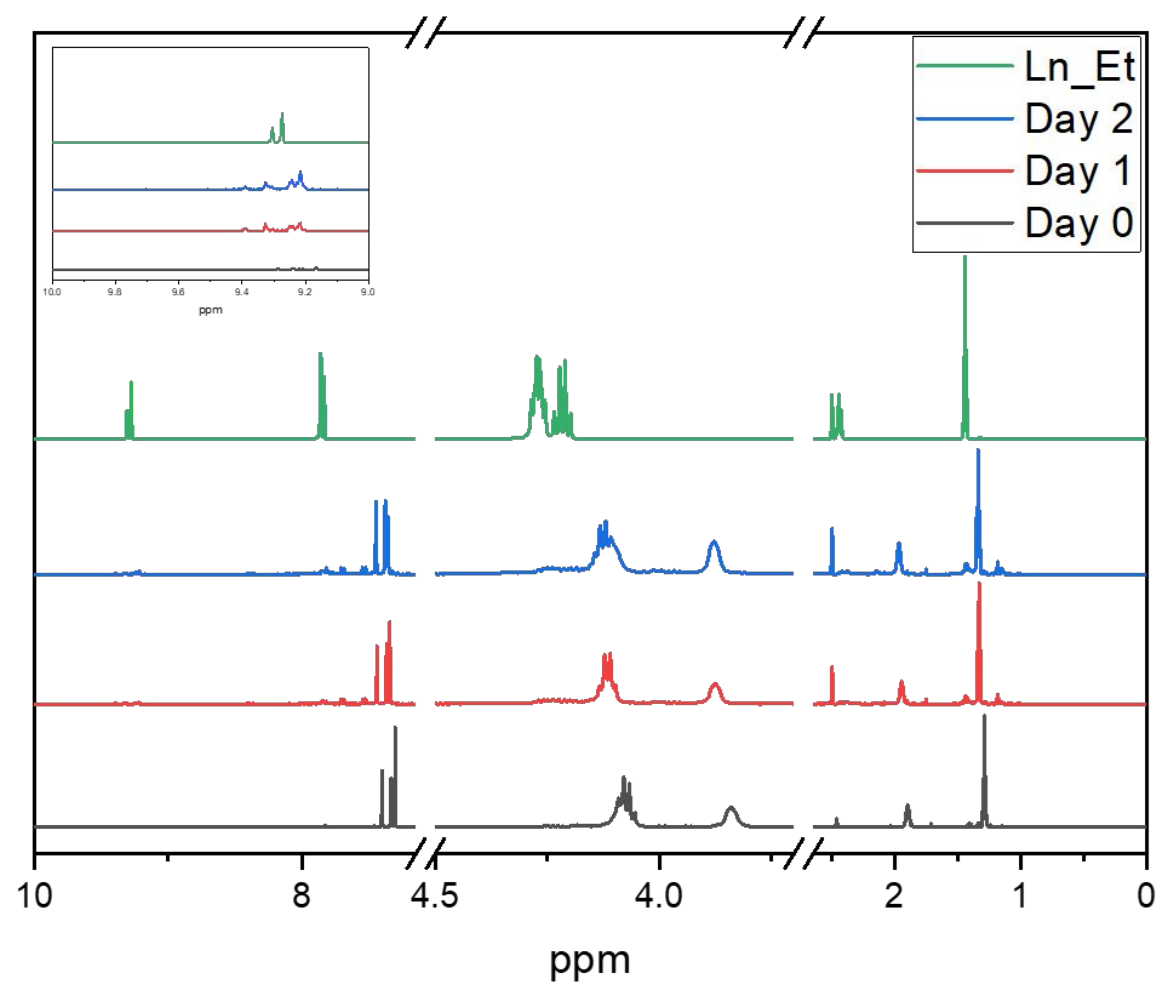

Figure S3. ${ }^{1} \mathrm{H}$ NMR spectra of the ligand (1,1'-((1H-imidazole-3-ium-1,3-diyl)bis(propane-3,1-diyl))bis(3-ethyl$1 H$-imidazol-3-ium) triiodide, $\mathbf{L n} \_\mathbf{E t}$ ) and complex $\mathbf{B}$ measured from the solution in $\mathrm{d}_{6}$-DMSO stored at room temperature for 0 to 2 days. The inset graphs are the enlarged spectra between 9 and $10 \mathrm{ppm}$. 


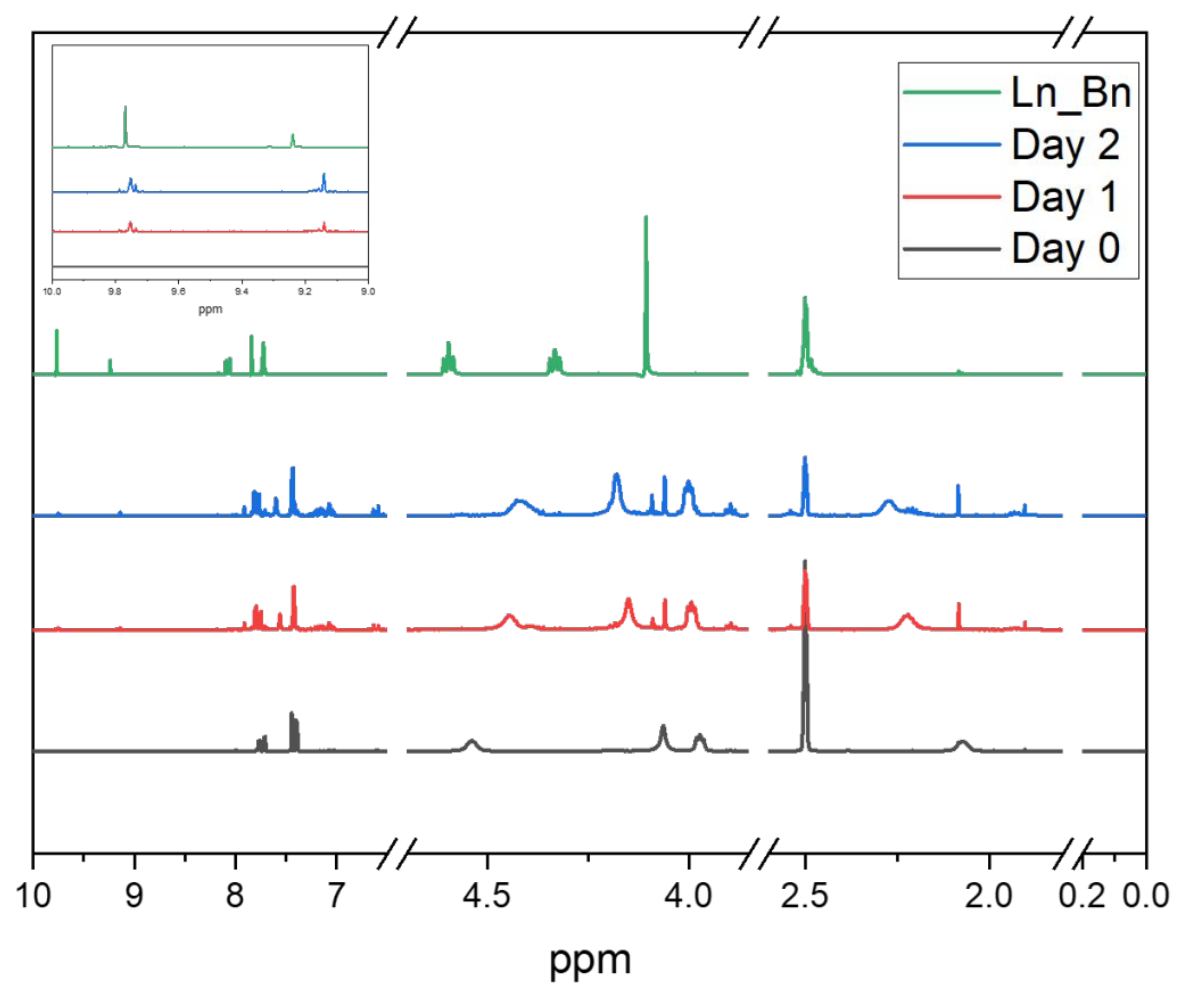

Figure S4. ${ }^{1} \mathrm{H}$ NMR spectra of the ligand (1,1'-((1H-imidazole-3-ium-1,3-diyl)bis(propane-3,1-diyl))bis(3-ehtyl$1 H$-benzo[d]imidazole-3-ium) triiodide, $\mathbf{L n} \_\mathbf{B n}$ ) and complex $\mathbf{C}$ measured from the solution in $\mathrm{d}_{6}$-DMSO stored at room temperature for 0 to 2 days. The inset graphs are the enlarged spectra between 9 and $10 \mathrm{ppm}$. 